\title{
Computational Selection of High-Performing Covalent Organic Frameworks for Adsorption and Membrane-Based $\mathrm{CO}_{2} / \mathrm{H}_{2}$ Separation
}

\author{
Gokhan Onder Aksu, Hilal Daglar, Cigdem Altintas, and Seda Keskin*
}

Cite This: J. Phys. Chem. C 2020, 124, 22577-22590

Read Online

ACCESS | 亗 Metrics \& More | 回 Article Recommendations | SI Supporting Information

ABSTRACT: Covalent organic frameworks (COFs) have high potential in gas separation technologies because of their porous structures, large surface areas, and good stabilities. The number of synthesized COFs already reached several hundreds, but only a handful of materials were tested as adsorbents and/or membranes. We used a high-throughput computational screening approach to uncover adsorption-based and membrane-based $\mathrm{CO}_{2} / \mathrm{H}_{2}$ separation potentials of $288 \mathrm{COFs}$, representing the highest number of experimentally synthesized COFs studied to date for precombustion $\mathrm{CO}_{2}$ capture. Grand canonical Monte Carlo (GCMC) simulations were performed to assess $\mathrm{CO}_{2} / \mathrm{H}_{2}$ mixture separation performances of COFs for five different cyclic adsorption

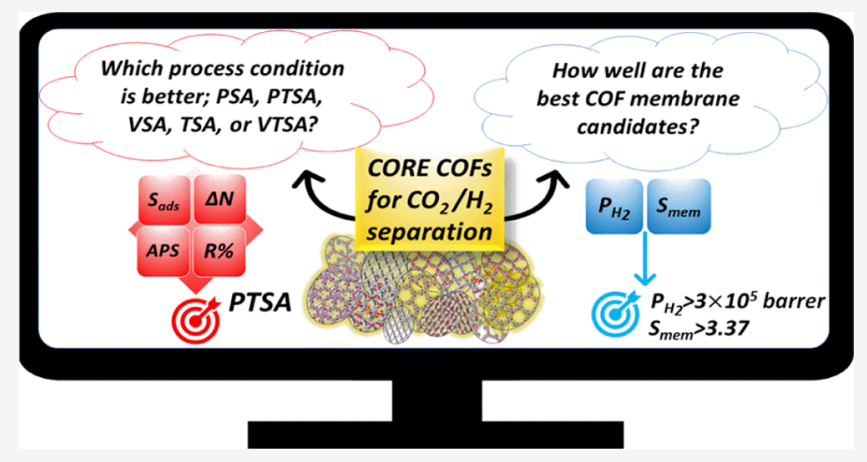
processes: pressure swing adsorption, vacuum swing adsorption,

temperature swing adsorption (TSA), pressure-temperature swing adsorption (PTSA), and vacuum-temperature swing adsorption (VTSA). The results showed that many COFs outperform traditional zeolites in terms of $\mathrm{CO}_{2}$ selectivities and working capacities and PTSA is the best process leading to the highest adsorbent performance scores. Combining GCMC and molecular dynamics (MD) simulations, $\mathrm{CO}_{2}$ and $\mathrm{H}_{2}$ permeabilities and selectivities of $\mathrm{COF}$ membranes were calculated. The majority of COF membranes surpass Robeson's upper bound because of their higher $\mathrm{H}_{2}$ permeabilities compared to polymers, indicating that the usage of COFs has enormous potential to replace current materials in membrane-based $\mathrm{H}_{2} / \mathrm{CO}_{2}$ separation processes. Performance analysis based on the structural properties showed that COFs with narrow pores [the largest cavity diameter (LCD) < $15 \AA$ ] and low porosities $(\phi<0.75)$ are the top adsorbents for selective separation of $\mathrm{CO}_{2}$ from $\mathrm{H}_{2}$, whereas materials with large pores (LCD $>20$ $\AA)$ and high porosities $(\phi>0.85)$ are generally the best COF membranes for selective separation of $\mathrm{H}_{2}$ from $\mathrm{CO}_{2}$. These results will help to speed up the engineering of new COFs with desired structural properties to achieve high-performance $\mathrm{CO}_{2} / \mathrm{H}_{2}$ separations.

\section{INTRODUCTION}

Separation of $\mathrm{CO}_{2}$ from $\mathrm{H}_{2}$ is important for various processes such as petroleum refining and production of hydrogen, methanol, or ammonia. ${ }^{1}$ For example, in the reaction of synthesis gas with steam, pure $\mathrm{H}_{2}$ and electricity are produced, while precombustion $\mathrm{CO}_{2}$ capture is necessary to remove $\mathrm{CO}_{2}$ from synthesis gas. ${ }^{2,3}$ Amine scrubbing is widely used for $\mathrm{CO}_{2}$ capture, but it is economically not feasible because of the high cost of solvent regeneration. ${ }^{4}$ Adsorption-based gas separation processes, such as pressure swing adsorption (PSA), vacuum swing adsorption (VSA), temperature swing adsorption (TSA), pressure-temperature swing adsorption (PTSA), and vacuum-temperature swing adsorption (VTSA), using porous materials are alternatives for $\mathrm{CO}_{2}$ capture. ${ }^{5-12}$ Zeolites and activated carbons are widely used as adsorbents for $\mathrm{CO}_{2}$ capture from syngas, but they generally suffer from low working capacities. ${ }^{13}$ Membrane-based separation is another option for $\mathrm{CO}_{2}$ capture and $\mathrm{H}_{2}$ purification. ${ }^{14}$ Polymers are widely used, but their performances are restricted by the trade- off between gas permeability and selectivity. ${ }^{15-17}$ Zeolite membranes offer higher $\mathrm{CO}_{2} / \mathrm{H}_{2}$ selectivities and permeabilities than polymers, ${ }^{18}$ but they have high manufacturing costs and limited tunability of the pore size. ${ }^{19}$ Therefore, it is highly required to discover new materials for adsorption and membrane-based separation of $\mathrm{CO}_{2} / \mathrm{H}_{2}$ mixtures.

Metal-organic frameworks (MOFs), composed of metal nodes connected with organic linkers, are considered as promising materials for various gas separations. ${ }^{20-23}$ Covalent organic frameworks (COFs) consist of lighter elements $(\mathrm{H}, \mathrm{C}$, $\mathrm{N}, \mathrm{O}$, and $\mathrm{B}$ ) and organic linkers that are covalently bonded. ${ }^{24}$ Compared to MOFs and other porous materials, most of the

Received: August 1, 2020

Revised: September 15, 2020

Published: September 18, 2020 
COFs have high porosities, good thermal stabilities, lower densities, and larger surface areas. ${ }^{25}$ Therefore, COFs can also be considered as potential adsorbents and membranes for gas separation applications. ${ }^{24,26}$ Experimental and computational work on COFs mostly concentrated on single-component and binary/ternary mixture separation on a small set of materials. $^{27-41}$ For example, molecular simulations showed that $\mathrm{CO}_{2} / \mathrm{CH}_{4}$ selectivities of five COFs are higher than those of zeolites (DD3R, MFI), nanoporous carbon $\left(\mathrm{C}_{168}\right.$ schwarzite) and a prototype MOF (IRMOF-1) based on the pure gas adsorption isotherm data. ${ }^{37} \mathrm{~A}$ total of $46 \mathrm{COFs}$ were studied to determine their $\mathrm{CO}_{2} / \mathrm{H}_{2}, \mathrm{CH}_{4} / \mathrm{H}_{2}$, and $\mathrm{CO}_{2} / \mathrm{CH}_{4}$ separation performances under PSA conditions, and COFs with high working capacities and selectivities were found to be comparable with zeolites and MOFs. ${ }^{42}$ Earlier computational studies showed that the BTP-COF membrane has a higher $\mathrm{CO}_{2}$ permeability than zeolite membranes such as MFI and CHA but a lower $\mathrm{CO}_{2} / \mathrm{H}_{2}$ selectivity. ${ }^{43} \mathrm{COF}-6$ was computed to have higher $\mathrm{CH}_{4} / \mathrm{H}_{2}$ selectivity compared to some MOF membranes, ${ }^{33}$ and it was predicted to have higher $\mathrm{CO}_{2}$ and $\mathrm{H}_{2}$ permeabilities than some polymers, zeolites, and MOF membranes for $\mathrm{CO}_{2} / \mathrm{CH}_{4}$ and $\mathrm{H}_{2} / \mathrm{CH}_{4}$ separations. ${ }^{44}$

The number of synthesized COFs has been continuously growing, and it is not practical to assess gas separation performances of a large number of COFs using purely experimental methods. High-throughput computational screening of materials is very useful to examine gas separation performances of a very large number of materials to guide the future experimental studies to the best candidates. Development of COF databases, computation-ready experimental COFs (CoRE COFs) ${ }^{45-47}$ and clean, uniform, and refined with automatic tracking from experimental database (CURATED) $\mathrm{COFs}^{48}$ facilitated computational screening of experimentally synthesized COFs for various applications. ${ }^{42,45-51}$ The CoRE COF database was screened for $\mathrm{CH}_{4}$ deliverable capacity ${ }^{46}$ and $\mathrm{H}_{2}$ storage. ${ }^{49}$ Computational screening of 187 CoRE COFs for adsorption-based noble gas separations under PSA and VSA conditions revealed that COFs can have high adsorption selectivities for $\mathrm{Kr} / \mathrm{Ar}, \mathrm{Xe} / \mathrm{Kr}$, and $\mathrm{Rn} / \mathrm{Xe}$ and high working capacities for $\mathrm{Kr}$ and $\mathrm{Xe}^{45} \mathrm{~A}$ total of $298 \mathrm{CoRE}$ COFs were investigated for $\mathrm{CO}_{2} / \mathrm{CH}_{4}$ separation, ${ }^{47}$ and it was found that $-\mathrm{F}$ and $-\mathrm{Cl}$ functional groups increased the membrane selectivities up to 2 orders of magnitude and carried several COF membranes over Robeson's upper bound ${ }^{17}$ which was defined for polymeric membranes. A total of 295 CoRE COFs were recently screened for $\mathrm{CO}_{2} / \mathrm{N}_{2}$ separation, and it was concluded that many COF adsorbents can compete with MOFs in $\mathrm{CO}_{2}$ capture from flue gas. ${ }^{51}$ A total of 296 CURATED COFs were also screened with a workflow algorithm to evaluate their postcombustion $\mathrm{CO}_{2}$ capture performances, and the $\mathrm{COF}$ with the lowest parasitic energy was identified for the PTSA process. ${ }^{48}$ Hypothetical (computer-generated but not yet synthesized) COFs were studied for $\mathrm{CH}_{4}$ storage. ${ }^{52,53}$ A total of $\sim 69,000$ hypothetical COF structures (hCOFs) were screened for $\mathrm{CO}_{2} / \mathrm{N}_{2}$ separation under PTSA conditions, and many hCOFs were found to have higher $\mathrm{CO}_{2}$ working capacities compared to CURATED COFs. ${ }^{54}$ As can be seen from this literature review, COFs have not been screened so far for adsorption- and membranebased $\mathrm{CO}_{2} / \mathrm{H}_{2}$ separation. We recently showed that a large number of MOFs can outperform zeolites and polymers in $\mathrm{CO}_{2} / \mathrm{H}_{2}$ separation processes. ${ }^{55}$ Similarity of COFs with MOFs in terms of structural properties makes COFs also potential adsorbents and membranes for $\mathrm{CO}_{2} / \mathrm{H}_{2}$ separation. Therefore, a comprehensive work aiming to unlock $\mathrm{CO}_{2} / \mathrm{H}_{2}$ separation performances of experimentally synthesized COFs is strongly needed to guide the selection of the best COF adsorbents and membranes for future studies.

In this work, we screened the CoRE COF database ${ }^{47}$ to distinguish the best $\mathrm{COF}$ adsorbents and membranes for $\mathrm{CO}_{2} /$ $\mathrm{H}_{2}$ separation. Grand canonical Monte Carlo (GCMC) simulations were performed to compute adsorption-based $\mathrm{CO}_{2}$ separation performances of COFs for the $\mathrm{CO}_{2} / \mathrm{H}_{2}: 15 / 85$ mixture under five different process conditions, PSA, VSA, TSA, PTSA, and VTSA. The selectivities, working capacities, adsorbent performance scores (APSs), and regenerabilities were computed for all COF adsorbents at each process condition and compared to elucidate how cyclic adsorption processes affect gas separation performances of COFs. The top 10 promising COFs were identified for each separation process based on the combination of different evaluation metrics. The effect of using different generic force fields in molecular simulation of COFs on the calculated adsorbent performance metrics was also examined. Molecular dynamics (MD) simulations were then performed to predict the performances of $\mathrm{COF}$ membranes for $\mathrm{H}_{2} / \mathrm{CO}_{2}$ separation. The selectivities and permeabilities of $\mathrm{COF}$ membranes were compared with those of zeolites and polymers, and the top $10 \mathrm{COF}$ membranes were identified. Finally, the relationship between selectivities and structural features of COFs was studied to describe the optimum structural properties for highly selective adsorbents and membranes. Our results will provide a molecular-level understanding of how $\mathrm{CO}_{2}$ and $\mathrm{H}_{2}$ adsorb and diffuse in COFs and guide the selection of highperforming COFs for five different swing adsorption processes in addition to the membrane-based precombustion $\mathrm{CO}_{2}$ capture process.

\section{COMPUTATIONAL DETAILS}

We used the third version of the CoRE COF database which consists of 309 COFs. ${ }^{47}$ First, structural features such as porelimiting diameter (PLD), the largest cavity diameter (LCD), accessible surface area $\left(S_{\text {acc }}\right)$, density $(\rho)$, and porosity $(\phi)$ of materials were estimated using Zeo++ software (version 0.3$).^{56}$ $S_{\text {acc }}$ was calculated using a probe that has the same kinetic diameter as the $\mathrm{N}_{2}$ molecule (3.64 $\AA$ ), and we eliminated the COFs with null accessible surface area. Then, the COF database was narrowed down to materials with PLDs larger than the kinetic diameter of the $\mathrm{CO}_{2}$ molecule, $3.3 \AA$, to allow the passage of both $\mathrm{CO}_{2}$ and $\mathrm{H}_{2}$ molecules in the framework. We note that the atomic coordinates of HAT-NTBA-COF were corrected following the literature. ${ }^{48,57}$ Overall, we ended up with 288 diverse COFs illustrating different chemical and structural features.

GCMC simulations were performed using RASPA simulation software ${ }^{58}$ (version 2.0.36) to obtain the $\mathrm{CO}_{2}$ and $\mathrm{H}_{2}$ uptakes in COFs. In order to represent the industrial precombustion gas mixture, the mole fractions of $\mathrm{CO}_{2}$ and $\mathrm{H}_{2}$ in the bulk mixture were set as 0.15 and 0.85 , respectively. ${ }^{59}$ Simulations were conducted at two different temperatures (298 and $393 \mathrm{~K}$ ) and three different pressures $\left(0.1,1\right.$, and 10 bar) to compute the $\mathrm{CO}_{2}$ and $\mathrm{H}_{2}$ uptakes of COFs for five different processes (PSA, VSA, TSA, PTSA, and VTSA), as given in detail in Table 1. Pressure was converted to fugacity by using the Peng-Robinson equation of state. ${ }^{58}$ Lennard-Jones (LJ) potential was used to specify dispersion 
Table 1. Adsorption-Desorption Conditions of Processes

$\begin{array}{lccc}\text { process } & \begin{array}{c}\text { adsorption pressure and } \\ \text { temperature }\end{array} & \begin{array}{c}\text { desorption pressure and } \\ \text { temperature }\end{array} & \text { references } \\ \text { PSA } & 10 \mathrm{bar}, 298 \mathrm{~K} & 1 \mathrm{bar}, 298 \mathrm{~K} & 11 \\ \text { VSA } & 1 \mathrm{bar}, 298 \mathrm{~K} & 0.1 \mathrm{bar}, 298 \mathrm{~K} & 11 \\ \text { TSA } & 1 \mathrm{bar}, 298 \mathrm{~K} & 1 \mathrm{bar}, 393 \mathrm{~K} & 7 \\ \text { PTSA } & 10 \mathrm{bar}, 298 \mathrm{~K} & 1 \mathrm{bar}, 393 \mathrm{~K} & 8,103 \\ \text { VTSA } & 1 \mathrm{bar}, 298 \mathrm{~K} & 0.1 \mathrm{bar}, 393 \mathrm{~K} & 104,105\end{array}$

interactions between all atoms, and Coulomb potential was used to define the electrostatic interactions between charged atoms. A single-site spherical model with the LJ 12-6 potential ${ }^{60}$ was used to model $\mathrm{H}_{2}$, while $\mathrm{CO}_{2}$ was modeled as a three-site linear, rigid molecule with a $\mathrm{C}-\mathrm{O}$ bond length of $1.16 \AA$ and partial point charges located at the center of each site. ${ }^{61}$ In our previous works, it was shown that both the universal force field (UFF) and Dreiding force field can be used for gas adsorption simulations of MOFs and COFs to reproduce the experimental gas uptakes. ${ }^{33,55}$ We computed the single-component adsorption isotherms of $\mathrm{CO}_{2}$ in three COFs (COF-5, COF-6, and COF-10) using both the UFF and Dreiding and compared our results with the available experimental data of these COFs. ${ }^{27}$ Figure $\mathrm{S} 1$ in the Supporting Information shows that computational $\mathrm{CO}_{2}$ uptakes are in better agreement with the experimental results when the Dreiding force field was used, and therefore, we used Dreiding for simulations of all COFs. Because $\mathrm{CO}_{2}$ has a quadrupole moment, the Coulomb potential was used to compute $\mathrm{CO}_{2}-\mathrm{CO}_{2}$ and $\mathrm{CO}_{2}-\mathrm{COF}$ electrostatic interactions. The partial point charges of the atoms of COFs were assigned using the charge equilibration method (Qeq) as implemented in RASPA. ${ }^{62}$ The long-range electrostatic interactions between $\mathrm{CO}_{2}$ molecules and COF atoms were calculated using the Ewald summation. ${ }^{63}$ Lorentz-Berthelot mixing rules were applied to define pairwise interactions between unlike atoms. A total of 30,000 cycles were used for GCMC simulations, while $10,000(20,000)$ cycles were used for initialization (taking ensemble averages). Here, we want to note that each cycle consists of a minimum of 20 and a maximum of $N$ steps, where $N$ implies the number of adsorbed molecules at each cycle. ${ }^{58}$ Translation, regrow, reinsertion, swap, and identity exchange moves were used in binary mixture simulations, while for $\mathrm{CO}_{2}$ molecules, the rotation move was also considered. $14 \AA$ was defined as the cutoff radius for intermolecular interactions as it has been previously used in high-throughput screening of $\mathrm{COFs}^{45-47}$ and each dimension of the simulation box was expanded to at least $28 \AA$ following the literature. ${ }^{64}$

To compute the gas permeabilities, we calculated the selfdiffusivities $\left(D_{\text {self }}\right)$ of $\mathrm{CO}_{2}$ and $\mathrm{H}_{2}$ in COFs by performing $\mathrm{MD}$ simulations. The gas uptakes acquired from binary mixture GCMC simulations at $10 \mathrm{bar}$ and $298 \mathrm{~K}$ were used for the mixture MD simulations. COFs were assumed to be rigid during $\mathrm{MD}$ simulations to reduce the computational cost. A total of $10^{6}$ cycles were used for both initialization and equilibration. MD simulations were carried out for $5 \times 10^{6}$ cycles in the NVT ensemble using a time step of $1 \mathrm{fs}$. A NoséHoover thermostat ${ }^{65}$ was used in MD simulations to keep the temperature constant. We obtained the mean-square displacement of gas molecules using the modified order- $N$ algorithm as implemented in RASPA ${ }^{58}$ which utilizes blocking averages to reduce statistical errors, ${ }^{64}$ and the self-diffusivities were calculated by Einstein's relation. ${ }^{66}$ To reduce uncertainties, simulations were performed twice.

We utilized various material performance evaluation metrics as listed in Table 2 to assess adsorption- and membrane-based

Table 2. Performance Metrics Computed To Evaluate COF Adsorbents and COF Membranes ${ }^{a}$

\begin{tabular}{|c|c|}
\hline metric & formula \\
\hline mixture adsorption selectivity & $S_{\mathrm{ads}, \mathrm{CO}_{2} / \mathrm{H}_{2}}^{\operatorname{mix}}=\frac{N_{\mathrm{CO}_{2}}}{N_{\mathrm{H}_{2}}} / \frac{y_{\mathrm{CO}_{2}}}{y_{\mathrm{H}_{2}}}$ \\
\hline working capacity & $\Delta N_{\mathrm{CO}_{2}}=N_{\mathrm{ads}, \mathrm{CO}_{2}}-N_{\text {des, } \mathrm{CO}_{2}}$ \\
\hline adsorbent performance score & $\mathrm{APS}=S_{\mathrm{ads}, \mathrm{CO}_{2} / \mathrm{H}_{2}}^{\mathrm{mix}} \times \Delta N_{\mathrm{CO}_{2}}$ \\
\hline percent regenerability & $R \%=\frac{\Delta N_{\mathrm{CO}_{2}}}{N_{\mathrm{ads}, \mathrm{CO}_{2}}} \times 100 \%$ \\
\hline mixture permeability & $P_{i}^{\text {mix }}=\frac{c_{i}^{\text {mix }} \times D_{i}^{\text {mix }}}{f_{i}}$ \\
\hline mixture diffusion selectivity & $S_{\mathrm{diff}, \mathrm{H}_{2} / \mathrm{CO}_{2}}^{\operatorname{mix}}=\frac{D_{\mathrm{H}_{2}}^{\mathrm{mix}}}{D_{\mathrm{CO}_{2}}^{\mathrm{mix}}}$ \\
\hline mixture membrane selectivity & $S_{\mathrm{mem}, \mathrm{H}_{2} / \mathrm{CO}_{2}}^{\operatorname{mix}}=\frac{P_{\mathrm{H}_{2}}^{\mathrm{mix}}}{P_{\mathrm{CO}_{2}}^{\mathrm{mix}}}$ \\
\hline
\end{tabular}

${ }^{a} N_{\text {ads }, i}:$ gas uptake under adsorption conditions $(\mathrm{mol} / \mathrm{kg}), N_{\text {des }, i}:$ gas uptake under desorption conditions $(\mathrm{mol} / \mathrm{kg}), D_{i}^{\text {mix }}$ : self-diffusivity of gas species in the mixture $\left(\mathrm{m}^{2} / \mathrm{s}\right), y$ : bulk composition of the gas mixture, $c_{i}^{\text {mix }}$ : molar concentration of adsorbed gas species $\left(\mathrm{mol} / \mathrm{m}^{3}\right)$, $f_{i}$ : partial pressure of gas species in the mixture $(\mathrm{Pa}) .1$ barrer $=3.348$ $\times 10^{-16} \mathrm{~mol} \cdot \mathrm{m} /\left(\mathrm{m}^{2} \cdot \mathrm{s} \cdot \mathrm{Pa}\right)$.

gas separation performances of COFs. One of the most important metrics to identify a good adsorbent is adsorption selectivity $\left(S_{\text {ads }}\right)$, and it was computed by dividing the uptake of the strongly adsorbed component $\left(\mathrm{CO}_{2}\right)$ by the uptake of the weakly adsorbed component $\left(\mathrm{H}_{2}\right)$, normalized by dividing with the bulk mixture composition, and represented as $S_{\mathrm{ads}, \mathrm{CO}_{2} / \mathrm{H}_{2}}$ in this work. Working capacity $(\Delta N)$ is important to determine the amount of gas that can be captured at each adsorption cycle. In this work, $\Delta N_{\mathrm{CO}_{2}}$ was calculated by taking the difference of $\mathrm{CO}_{2}$ loadings under adsorption and desorption conditions given in Table 1 . To approximate the performance of COFs for the PTSA and VTSA processes, GCMC simulation results obtained from three different conditions (both pressure and temperature difference) were used. ${ }^{67}$ The APS was obtained by multiplying the selectivity and working capacity. ${ }^{68}$ Percent regenerability $(R \%)$ is the ratio of working capacity to the gas uptake at the adsorption pressure. $^{69}$ The performances of COF membranes were evaluated using the gas permeabilities $\left(P_{i}\right)$ and membrane selectivities $\left(S_{\text {mem }}\right)$. The $\mathrm{CO}_{2}$ and $\mathrm{H}_{2}$ permeabilities were calculated by using the results obtained from GCMC and $\mathrm{MD}$ simulations. Membrane selectivity was defined as the ratio of permeability of the more permeable gas species to permeability of the less permeable one, as provided in Table $2 .^{70}$ The permeability of $\mathrm{H}_{2}$ is greater than the permeability of $\mathrm{CO}_{2}$ in COFs; therefore, membrane selectivities were reported as $\mathrm{H}_{2}$ / $\mathrm{CO}_{2}\left(S_{\mathrm{mem}, \mathrm{H}_{2} / \mathrm{CO}_{2}}\right)$. The steps of our computational work are provided in Scheme S1 of the Supporting Information. 

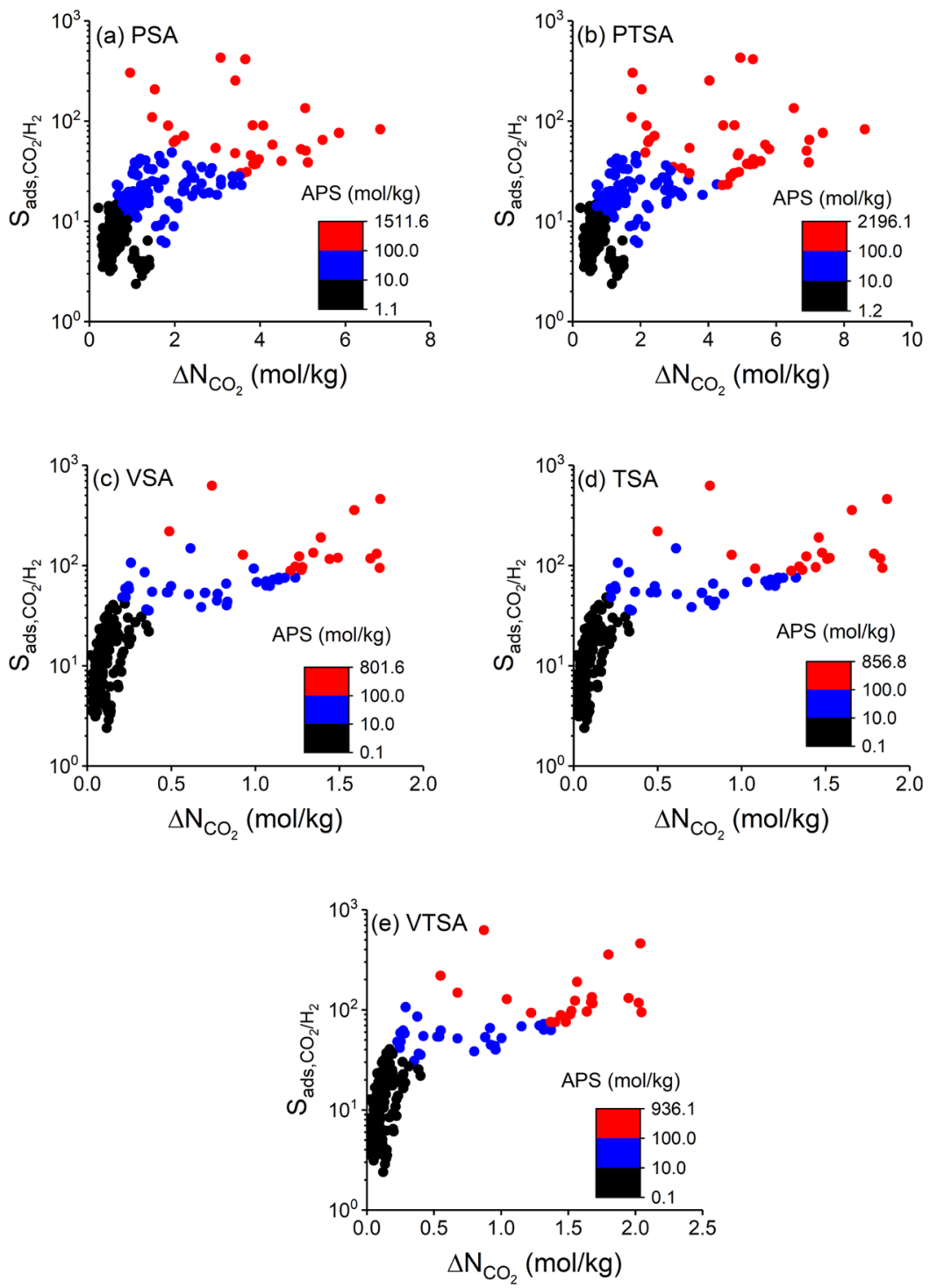

Figure 1. Relation between $S_{\text {ads, } \mathrm{CO}_{2} / \mathrm{H}_{2}}, \Delta N_{\mathrm{CO}_{2}}$, and APS of COFs for the $\mathrm{CO}_{2} / \mathrm{H}_{2}: 15 / 85$ mixture under (a) PSA, (b) PTSA, (c) VSA, (d) TSA, and (e) VTSA conditions. Black, blue, and red data show COFs with APS $<10(\mathrm{~mol} / \mathrm{kg}), 10<$ APS $<100(\mathrm{~mol} / \mathrm{kg})$, and APS $>100(\mathrm{~mol} / \mathrm{kg})$, respectively.

\section{RESULTS AND DISCUSSION}

3.1. COF Adsorbents. We evaluated COF adsorbents for five different adsorption-based separation processes. In the PSA and VSA processes, adsorbed gases are desorbed by lowering the pressure at constant temperature. TSA is based on the temperature difference between adsorption and desorption steps, and gas molecules are desorbed upon heating, while pressure is kept constant. The combination of PSA or VSA with TSA, named PTSA and VTSA, is useful to have a good regeneration of adsorbents. We compared the performances of COF adsorbents under all these process conditions to elucidate the optimum process condition for high-efficiency $\mathrm{CO}_{2} / \mathrm{H}_{2}$ separation using COFs. The most promising adsorbents should provide both high $S_{\mathrm{ads}, \mathrm{CO}_{2} / \mathrm{H}_{2}}$ and high $\Delta N_{\mathrm{CO}_{2}}$. Figure 1 shows the relation between $S_{\mathrm{ads}, \mathrm{CO}_{2} / \mathrm{H}_{2}}$ and $\Delta N_{\mathrm{CO}_{2}}$ for different processes, and the general trend for all processes is that COFs with high $S_{\mathrm{ads}, \mathrm{CO}_{2} / \mathrm{H}_{2}}$ suffer from low $\Delta N_{\mathrm{CO}_{2}}$ and vice versa. COFs which offer moderate $S_{\mathrm{ads}, \mathrm{CO}_{2} / \mathrm{H}_{2}}$ and $\Delta \mathrm{N}_{\mathrm{CO}_{2}}$ have APSs between 10 and $100 \mathrm{~mol} / \mathrm{kg}$. According to Figure $1 \mathrm{a}, \mathrm{b}, \mathrm{APS}$ s of COFs under PSA and PTSA conditions show a similar trend, while Figure 1c-e shows that APSs under VSA, TSA, and VTSA conditions are more alike. Therefore, we discussed these processes separately as under (i) PSA and PTSA and (ii) VSA, TSA, and VTSA conditions.

Because the adsorption conditions are the same for the PSA and PTSA processes, as provided in Table 1 , the $S_{\text {ads, } \mathrm{CO}_{2} / \mathrm{H}_{2}}$ values are the same and computed as $2.38-428$. The $\Delta N_{\mathrm{CO}_{2}}$ values of COFs under PSA conditions $(0.21-6.82 \mathrm{~mol} / \mathrm{kg})$ are lower than those under PTSA conditions $(0.23-8.61 \mathrm{~mol} / \mathrm{kg})$. This is expected because increasing the temperature under desorption conditions results in an increase in the amount of desorbed gas, which increases $\Delta N_{\mathrm{CO}_{2}}{ }^{71}$ Black, blue, and red points represent COFs offering low $(<10 \mathrm{~mol} / \mathrm{kg})$, moderate (between 10 and $100 \mathrm{~mol} / \mathrm{kg}$ ), and high $(>100 \mathrm{~mol} / \mathrm{kg})$ APSs, respectively. A total of 32 (40) out of 288 COFs offer the highest APSs ( $>100 \mathrm{~mol} / \mathrm{kg}$ ) under PSA (PTSA) conditions. COFs with high APSs $(>100 \mathrm{~mol} / \mathrm{kg}$ ) under PSA (PTSA) 
Table 3. Comparison of Molecular Simulation Results for Zeolites, MOFs, and hMOFs for Syngas Separations

\begin{tabular}{|c|c|c|c|c|}
\hline material & $S_{\mathrm{ads}, \mathrm{CO}_{2} / \mathrm{H}_{2}}$ & condition & $\Delta N_{\mathrm{CO}_{2}}(\mathrm{~mol} / \mathrm{kg})$ & references \\
\hline $\mathrm{NaX}$ & 1257 & $\mathrm{CO}_{2} / \mathrm{H}_{2}: 15 / 85,300 \mathrm{~K}$ & $1.26^{a}$ & 77 \\
\hline $\mathrm{NaY}$ & 540 & $\mathrm{CO}_{2} / \mathrm{H}_{2}: 15 / 85,300 \mathrm{~K}$ & $2.69^{a}$ & 77 \\
\hline AFX & 505.5 & $\mathrm{CO}_{2} / \mathrm{H}_{2}: 15 / 85,300 \mathrm{~K}$ & $3.42^{a}$ & 77 \\
\hline $\mathrm{CHA}$ & 117.4 & $\mathrm{CO}_{2} / \mathrm{H}_{2}: 15 / 85,300 \mathrm{~K}$ & $2.69^{a}$ & 77 \\
\hline GME & 97.2 & $\mathrm{CO}_{2} / \mathrm{H}_{2}: 15 / 85,300 \mathrm{~K}$ & $2.25^{a}$ & 77 \\
\hline MOR & 134.1 & $\mathrm{CO}_{2} / \mathrm{H}_{2}: 15 / 85,300 \mathrm{~K}$ & $0.84^{a}$ & 77 \\
\hline MFI & 95.4 & $\mathrm{CO}_{2} / \mathrm{H}_{2}: 15 / 85,300 \mathrm{~K}$ & $1.25^{a}$ & 77 \\
\hline FAU & 17 & $\mathrm{CO}_{2} / \mathrm{H}_{2}: 15 / 85,300 \mathrm{~K}$ & $0.67^{a}$ & 77 \\
\hline MOFs & 2.43 to $2.4 \times 10^{4}$ & $\mathrm{CO}_{2} / \mathrm{H}_{2}: 15 / 85,298 \mathrm{~K}$ & $1 \times 10^{-3}$ to $11.28^{a}$ & 55 \\
\hline MOFs & 2.47 to $8.4 \times 10^{4}$ & $\mathrm{CO}_{2} / \mathrm{H}_{2}: 15 / 85,298 \mathrm{~K}$ & $7 \times 10^{-3}$ to $4.60^{b}$ & 55 \\
\hline hMOFs & $1.62-717.3$ & $\mathrm{CO}_{2} / \mathrm{H}_{2}: 20 / 80,313 \mathrm{~K}$ & $7 \times 10^{-3}$ to $7.78^{c}$ & 68 \\
\hline $\mathrm{hMOFs}^{e}$ & $0.001-337.5$ & $\mathrm{CO}_{2} / \mathrm{H}_{2}: 40 / 60,313 \mathrm{~K}$ & $0.76-38.77^{d}$ & 76 \\
\hline
\end{tabular}

${ }^{a}$ Working capacity is reported between 10 and 1 bar. ${ }^{b}$ Working capacity is reported between 1 and 0.1 bar. ${ }^{c}$ Working capacity is reported between 20 and 1 bar. ${ }^{d}$ Working capacity is reported between 40 and 1 bar. ${ }^{e}$ Predicted by the gradient-boosted trees regression method.

conditions have $S_{\mathrm{ads}, \mathrm{CO}_{2} / \mathrm{H}_{2}}$ between 30.1 and 428 (22.9-428) and $\Delta \mathrm{N}_{\mathrm{CO}_{2}}$ between 0.95 and $6.82(1.74-8.61) \mathrm{mol} / \mathrm{kg}$. Similar to the APS, a high $R \%$ is also required for efficient adsorption-based gas separation processes. We previously showed that MOFs with high APSs generally suffer from low $R \%{ }^{55}$ Figure S2a shows that most COFs (244 out of 288) have $R \%>85 \%$, but those with high APSs $(>100 \mathrm{~mol} / \mathrm{kg}$ ) have a low $R \%$ under PSA conditions. On the other hand, Figure S2b shows that all COFs have $R \%>85 \%$ as the lowest $R \%$ was computed as $95 \%$ under PTSA conditions. This is due to the combination of temperature and pressure swing in PTSA which leads to higher $\Delta N_{\mathrm{CO}_{2}}$ and a higher $R \%$ compared to the PSA process.

The most promising COF adsorbents offering $R \%>85 \%$ together with the highest APSs were identified for each process condition. The top 10 COFs for PSA and PTSA conditions are highlighted in Figure S2a,b and listed in Tables S1 and S2, with

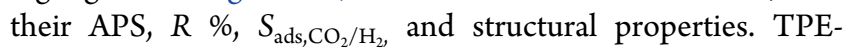
COF- $\mathrm{I}^{72}$ was identified as the best COF for the PSA process. Because of its narrower pores (LCD: 7.82 $\AA$, PLD: $7.17 \AA$ ) and lower porosity $(0.60)$ compared to other COFs, adsorption of $\mathrm{CO}_{2}$ molecules is favored in TPE-COF-I, resulting in enhanced selectivity. $\mathrm{TpPa}^{-\mathrm{F}_{4}}{ }^{73}$ is another $\mathrm{COF}$ among the top 10 materials offering high performance for $\mathrm{CO}_{2} / \mathrm{H}_{2}$ separation under PSA conditions. $S_{\mathrm{ads}, \mathrm{CO}_{2} / \mathrm{H}_{2}}$ and $\Delta \mathrm{N}_{\mathrm{CO}_{2}}$ were computed as 64.7 and $2.03 \mathrm{~mol} / \mathrm{kg}$, respectively, for this COF which is functionalized with fluorine (F) atoms. These functional groups contribute to the electrostatic interactions and enhanced $\mathrm{CO}_{2}$ selectivity. To represent this, we repeated GCMC simulations by neglecting $\mathrm{CO}_{2}-\mathrm{COF}$ electrostatic interactions for all COFs and then compared their selectivities, as shown in Figure S3. Neglecting the framework charges significantly underestimates the selectivities of many COFs at both 1 and 10 bar, as shown in Figure S3a,b, respectively. When the Coulomb interactions were not considered, $S_{\mathrm{ads}, \mathrm{CO}_{2} / \mathrm{H}_{2}}$ of $\mathrm{TpPa}-\mathrm{F}_{4}$ dramatically decreased from 64.7 to 11.3 at 10 bar because of the decrease in $\mathrm{CO}_{2}$ adsorption. Similarly, when the framework charges were absent, another top COF functionalized with $\mathrm{F}$ atoms, EB-COF:F, ${ }^{74}$ was computed to have a lower $S_{\mathrm{ads}, \mathrm{CO}_{2} / \mathrm{H}_{2}}$ (15.1) than the one calculated by considering electrostatic interactions (61.6). We also provided snapshots for adsorption of $\mathrm{CO}_{2}$ and $\mathrm{H}_{2}$ molecules in EB-COF:F with and without electrostatic interactions under PSA conditions, as shown in Figure S4. $\mathrm{CO}_{2}$ molecules mostly gather close to the pore walls because of their stronger intermolecular interactions with the framework atoms than $\mathrm{H}_{2}$ molecules. These results showed that $\mathrm{CO}_{2}-$ $\mathrm{COF}$ electrostatic interactions play a major role in determining selectivities and hence identification of the top COFs.

Interestingly, when the top COFs of the PSA and PTSA processes were compared, no common material was found. For the PTSA process, NPN- $2^{75}$ was found to be the best COF with an $S_{\mathrm{ads}, \mathrm{CO}_{2} / \mathrm{H}_{2}}$ of 413 and a $\Delta N_{\mathrm{CO}_{2}}$ of $5.31 \mathrm{~mol} / \mathrm{kg}$. The other two top COFs, NPN-1 and NPN-3, also have high $S_{\text {ads, } \mathrm{CO}_{2} / \mathrm{H}_{2}}$, which can be attributed to their narrow pore sizes (between 4.11 and 6.14 ̊). ${ }^{42,75}$ Under PSA conditions, NPN-2 has the highest APS among all COFs, but it is not one of the best COFs because of its low $R \%$. This is because of the desorption condition of PSA ( 1 bar, $298 \mathrm{~K}$ ) at which $\mathrm{CO}_{2}$ molecules cannot desorb enough, leading to a low $\Delta \mathrm{N}_{\mathrm{CO}_{2}}$ and a low $R \%$. When we examined the performances of all the top COF adsorbents of the PTSA process under PSA conditions, we noticed that they cannot be categorized as the top materials for PSA because of their low $R \%$. Although COFs offer the same selectivity under both PSA and PTSA conditions, they have higher $\Delta \mathrm{N}_{\mathrm{CO}_{2}}$ and $R \%$ under PTSA conditions compared to those under PSA conditions. Therefore, COFs offering high $S_{\mathrm{ads}, \mathrm{CO}_{2} / \mathrm{H}_{2}}$ become prominent as the top adsorbents for $\mathrm{CO}_{2} /$ $\mathrm{H}_{2}$ separation under PTSA conditions. We also compared the selectivities and working capacities of COFs that we examined in this work with those of zeolites, MOFs, and hypothetical MOFs (hMOFs) taken from the literature, as listed in Table 3. The results revealed that many COFs have better/similar performances than/to zeolites and hMOFs under PSA conditions, whereas MOFs generally have higher selectivities than COFs. ${ }^{55,68,76,77}$

Figure $1 \mathrm{c}-\mathrm{e}$ shows the relationship between $S_{\mathrm{ads}, \mathrm{CO}_{2} / \mathrm{H}_{2}}$ and $\Delta N_{\mathrm{CO}_{2}}$ under VSA, TSA, and VTSA conditions, respectively. These processes have the same adsorption condition ( 1 bar, $298 \mathrm{~K})$, and therefore, COFs have the same $S_{\mathrm{ads}, \mathrm{CO}_{2} / \mathrm{H}_{2}}$ range, 2.39-625. The $\Delta \mathrm{N}_{\mathrm{CO}_{2}}$ values of COFs under VSA (TSA) conditions were computed to be between 0.02 and $1.74 \mathrm{~mol} /$ $\mathrm{kg}(0.02-1.86 \mathrm{~mol} / \mathrm{kg})$. Slightly higher $\Delta \mathrm{N}_{\mathrm{CO}_{2}}$ values were observed under VTSA conditions, $0.02-2.05 \mathrm{~mol} / \mathrm{kg}$. All COFs offering APS $>100 \mathrm{~mol} / \mathrm{kg}$ under VSA conditions have 

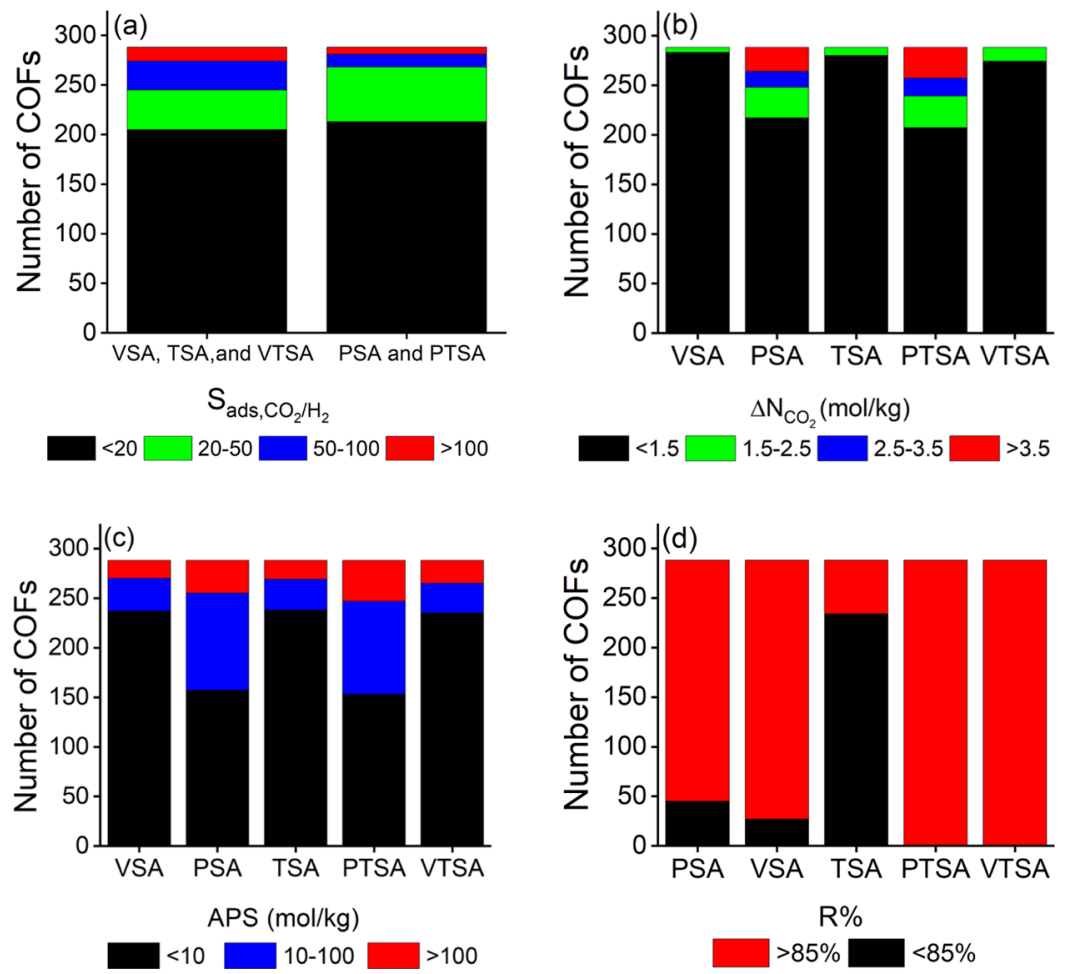

Figure 2. Distribution of (a) $S_{\mathrm{ads}, \mathrm{CO}_{2} / \mathrm{H}_{2}}$, (b) $\Delta N_{\mathrm{CO}_{2}}$, (c) APS, and (d) $R \%$ for each adsorption-based separation process.

APS $>100 \mathrm{~mol} / \mathrm{kg}$ under TSA and VTSA conditions as well. The relation between $R \%$ and APSs of COFs under VSA, TSA, and VTSA conditions is shown in Figure S2c-e, respectively. COFs with high APSs have low $R \%$ under VSA conditions. However, a different trend was observed under TSA conditions such that COFs with high APSs also have high $R \%$ and vice versa. The residual adsorbed amount of $\mathrm{CO}_{2}$ under desorption conditions $\left(\mathrm{N}_{\mathrm{des}, \mathrm{CO}_{2}}\right)$ is the only term varying for these two processes because the desorption conditions of VSA (0.1 bar, $298 \mathrm{~K})$ and TSA (1 bar, $393 \mathrm{~K})$ are different, while the adsorption condition is the same ( 1 bar, $298 \mathrm{~K}$ ). Therefore, we investigated the trends of $N_{\text {des, } \mathrm{CO}_{2}}$ under the desorption conditions of TSA and VSA, as shown in Figure S5a. For most of the COFs, the temperature difference between adsorption and desorption conditions of the TSA process leads to higher $N_{\text {des, } \mathrm{CO}_{2}}$ and lower $\Delta N_{\mathrm{CO}_{2}}$ values compared to $N_{\text {des, } \mathrm{CO}_{2}}$ values obtained with the pressure change of the VSA process. In other words, we observed that more $\mathrm{CO}_{2}$ is still adsorbed at $1 \mathrm{bar}$ and $393 \mathrm{~K}$ than at $0.1 \mathrm{bar}$ and $298 \mathrm{~K}$ for most of the COFs. This causes lower $\Delta N_{\mathrm{CO}_{2}}$ and a lower $R \%$ under TSA conditions compared to those under VSA conditions and shows that pressure swing is more effective than temperature swing for the desorption of $\mathrm{CO}_{2}$ molecules. As a result, the number of COFs with $R \%>85 \%$ under VSA conditions is more than that under TSA conditions, as shown in Figure S5b. On the other hand, all COFs have high $R \%$ values ( $>95 \%)$ under VTSA conditions, similar to PTSA.

The number of COFs with $R \%>85 \%$ is 262 (53) under VSA (TSA) conditions. The top 10 COFs with the highest APSs while $R \%>85 \%$ are shown by red points in Figure S2ce for VSA, TSA, and VTSA conditions, respectively. These top adsorbents are also listed in Tables S3-S5. There are four common top materials for these processes, NPN-2, ${ }_{78}^{75} \mathrm{COF}-42-$ gra, ${ }^{78}$ FLT-COF-1-staggered, ${ }^{79}$ and COF-JLU- $3 .{ }^{80}$ We observed that staggered modes in COF-42-gra and FLT-COF-1staggered favor the adsorption of $\mathrm{CO}_{2}$ molecules. The eclipsed modes of these two COFs, COF-42-bnn and FLT-COF-1eclipsed, have lower $S_{\mathrm{ads}, \mathrm{CO}_{2} / \mathrm{H}_{2}}$ and $\mathrm{CO}_{2}$ uptakes than the staggered ones because narrower pores of staggered modes favor the confinement of $\mathrm{CO}_{2}$ molecules compared to the eclipsed mode of the same COFs. Postsynthetic modifications are very important to increase the productivity of COFs for separation applications. ${ }^{81}$ 3D-COOH-COF is another top COF for the TSA and VTSA processes, and it is a postsynthetic carboxylated version of 3D-OH-COF. ${ }^{82}$ When we compared their adsorption selectivities, $S_{\mathrm{ads}, \mathrm{CO}_{2} / \mathrm{H}_{2}}$ of $3 \mathrm{D}$ COOH-COF (625) is much larger than $S_{\mathrm{ads}, \mathrm{CO}_{2} / \mathrm{H}_{2}}$ of its predecessor (27.6), and it can be attributed to the additional adsorption sites provided by the carboxylate groups of $3 \mathrm{D}$ COOH-COF. Four materials, NPN-2, COF-42-gra, FLTCOF-1-staggered, and COF-JLU-3 among 288 COFs, were found to be promising for all processes except the PSA process. As mentioned before, the selectivities were underestimated when Coulombic interactions between COFs and $\mathrm{CO}_{2}$ molecules were neglected, and the selectivities of the top materials for the VSA, TSA, and VTSA processes such as 3D$\mathrm{COOH}-\mathrm{COF}$ and FLT-COF-1-staggered also decreased at 1 bar as shown in Figure S3a.

The distribution and ranges of $S_{\mathrm{ads}, \mathrm{CO}_{2} / \mathrm{H}_{2}}, \Delta N_{\mathrm{CO}_{2}}$, APSs, and $R \%$ under PSA, VSA, TSA, PTSA, and VTSA conditions are provided in Figure 2 and Table 4. Figure 2a illustrates that COFs tend to have higher $S_{\mathrm{ads}, \mathrm{CO}_{2} / \mathrm{H}_{2}}(>50)$ under VSA, TSA, and VTSA conditions compared to those under PSA and PTSA conditions. On the other hand, the $\Delta N_{\mathrm{CO}_{2}}$ values of COFs under PSA and PTSA conditions are much larger than 
Table 4. Ranges of Performance Metrics Computed with Molecular Simulation Results for 288 COFs under PSA, VSA, TSA, PTSA, and VTSA Conditions

\begin{tabular}{ccccc} 
condition & $S_{\mathrm{ads}, \mathrm{CO}_{2} / \mathrm{H}_{2}}$ & $\Delta N_{\mathrm{CO}_{2}}(\mathrm{~mol} / \mathrm{kg})$ & $\mathrm{APS}(\mathrm{mol} / \mathrm{kg})$ & $\mathrm{R}(\%)$ \\
PSA & $2.38-428$ & $0.21-6.82$ & $1.10-1511$ & $52.0-91.1$ \\
VSA & $2.39-625$ & $0.02-1.74$ & $0.11-801$ & $76.3-90.8$ \\
TSA & $2.39-625$ & $0.02-1.86$ & $0.08-857$ & $50.3-92.5$ \\
PTSA & $2.38-428$ & $0.23-8.61$ & $1.17-2196$ & $94.8-98.9$ \\
VTSA & $2.39-625$ & $0.02-2.05$ & $0.12-936$ & $95.6-99.2$ \\
\hline
\end{tabular}

those under VSA, TSA, and VTSA conditions as shown in Figure $2 \mathrm{~b}$. Figure $2 \mathrm{c}$ shows that there are more COFs with mediocre $(>10 \mathrm{~mol} / \mathrm{kg})$ and high APSs $(>100 \mathrm{~mol} / \mathrm{kg})$ under PSA and PTSA conditions compared to VSA, TSA, and VTSA conditions. In other words, among the five different cyclic adsorption processes we considered, COFs perform as the best in the PSA and PTSA processes. It is important to note that the main factor determining the APS trends of different processes is $\Delta \mathrm{N}_{\mathrm{CO}_{2}}$. For example, COF-42-gra has a high APS under PTSA conditions $(877 \mathrm{~mol} / \mathrm{kg})$, which is almost triple of its corresponding APS under VTSA conditions $(298 \mathrm{~mol} / \mathrm{kg})$. $S_{\mathrm{ads}, \mathrm{CO}_{2} / \mathrm{H}_{2}}$ of this COF under VTSA conditions (190) is larger than the one calculated under PTSA conditions (134). Because $\Delta N_{\mathrm{CO}_{2}}$ of this COF under PTSA conditions $(6.52 \mathrm{~mol} / \mathrm{kg})$ is much larger than its $\Delta N_{\mathrm{CO}_{2}}$ under VTSA conditions (1.57 $\mathrm{mol} / \mathrm{kg}$ ), COF-42-gra has a higher APS and performs better under PTSA conditions compared to VTSA conditions. Overall, the highest APSs were obtained under PSA and PTSA conditions for adsorption-based $\mathrm{CO}_{2} / \mathrm{H}_{2}$ mixture separation using COFs. Figure $2 \mathrm{~d}$ shows that all COFs have high $R \%$ under PTSA and VTSA conditions. As discussed before, the addition of temperature swing to the pressure swing process enhances $\mathrm{CO}_{2}$ desorption and leads to high $R \%$. However, another important factor is that materials used in temperature swing processes should have high thermal stabilities because of high operating temperatures. We examined that COFs listed as our top materials for the TSA, PTSA, and VTSA processes have very good thermal stabilities up to $500{ }^{\circ} \mathrm{C}$ except NPN-group COFs which have thermal stabilities around $140{ }^{\circ} \mathrm{C} .{ }^{75,78-80,82-88}$

As previously mentioned, molecular simulations using Dreiding agreed better with the reported experimental gas uptakes. We further investigated how using a different generic force field for the COFs can affect the simulation results. GCMC simulations were repeated using UFF parameters, and the adsorbent performance metrics were recalculated for all COFs under VSA conditions. Our group previously reported that the quantitative values of performance metrics obtained by using the UFF or Dreiding can be significantly different; however, ranking of materials may not significantly change. ${ }^{89}$ Thus, we specifically focused on the effect of using Dreiding or UFF parameters on ranking of COF adsorbents and computed Spearman's ranking correlation coefficient (SRCC) that compares the rankings of COFs as shown in Table S6. The results show that rankings of COFs based on $\mathrm{S}_{\mathrm{ads}, \mathrm{CO}_{2} / \mathrm{H}_{2}}$, $\Delta N_{\mathrm{CO}_{2}}$, and APSs are highly similar, resulting in SRCC $>0.95$. However, SRCC of material ranking based on $R \%$ was calculated as 0.53 , indicating that ranking of COFs based on $R$ $\%$ would be very dissimilar when a different generic force field was used. In order to better understand the effect of force field on the identification of the most promising COFs, we compared the $R \%$ values obtained from GCMC simulations using Dreiding and the UFF, as shown in Figure 3. A total of 8

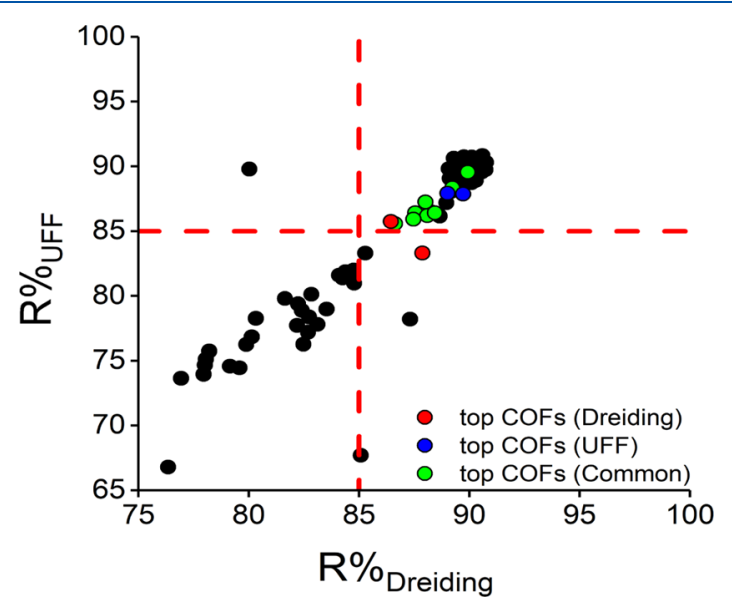

Figure 3. Comparison of the top COFs identified from simulations using Dreiding or the UFF for the VSA process. Red and blue data represent the top materials identified from simulations using Dreiding or the UFF, respectively, whereas green data represent the common top materials identified from simulations using Dreiding or UFF parameters.

of the top 10 materials are the same when either of the force fields was used; however, if we used the UFF, some COFs would not be distinguished as the top. For instance, PyTTA$\mathrm{BFBIm}$-iCOF was identified as a top COF for the VSA process when simulations were performed with Dreiding. However, it was not among the top COFs when the UFF was used (Table $S 7$ ) because its $R \%$ was computed to be $<85 \%$. Overall, these results showed that force field selection can be important if the COFs are ranked based on $R \%$.

Adsorption-based gas separation has multiple requirements including low cost, high purity, and cyclic usage of the adsorbent, and real-time experimental techniques, such as utilization of fixed-bed adsorption units, generally focus on the working capacity and the selectivity of the material. ${ }^{90}$ To identify the most promising adsorbents among many candidates for adsorption-based gas separation using highthroughput computational screening, adsorbent performance evaluation metrics such as adsorption selectivity, working capacity, and regenerability are generally used. ${ }^{69,90-92}$ High selectivity values help to identify the adsorbents which can provide high-purity separation, while high working capacity and high regenerability values indicate that the adsorbent can be used several times with high productivity. Because of the differences between experimental and computational setups (fluctuations in the temperature or pressure, impurity of the gas feed, defects in the adsorbent material, or diffusional limitations), one can expect that calculated adsorbent performance evaluation metrics represent the approximate performance of the adsorbent and they may not perfectly reflect the real-time experimental performance. The aim of our work was to highlight the most promising COF adsorbents among several hundred adsorbents via utilizing these simulated metrics, and a more detailed analysis can be made on the top material candidates. Finally, it is important to note that the method that we used to assign partial atomic charges to framework atoms can be critical for the calculated values of 
adsorbent performance evaluation metrics. In our recent work, we showed that although the ranking of materials does not change significantly, the choice of the charge method can overestimate/underestimate the performance values of materials. ${ }^{51,93}$ Therefore, it would be a good practice to test the performances of the most promising COF adsorbents by using high-quality partial charges, such as density-derived electrostatic and chemical (DDEC) charges assigned to CURATED COFs, before experimental efforts.

3.2. COF Membranes. Membranes are alternatively used for $\mathrm{CO}_{2} / \mathrm{H}_{2}$ mixture separation because of different molecular sizes of $\mathrm{H}_{2}(2.9 \AA)$ and $\mathrm{CO}_{2}(3.3 \AA)$ and their molar compositions in the industrial gas streams. We investigated the membrane performances of COFs for $\mathrm{H}_{2} / \mathrm{CO}_{2}$ separation at 10 bar and $298 \mathrm{~K}$. Because $\mathrm{H}_{2}$ molecules are lighter than $\mathrm{CO}_{2}$ molecules, they diffuse faster than $\mathrm{CO}_{2}$ through the membrane pores; ${ }^{94}$ thus, we concentrated on the $\mathrm{H}_{2} / \mathrm{CO}_{2}$ selectivity of $\mathrm{COF}$ membranes. Membrane selectivity is a product of adsorption and diffusion selectivity; Figure 4 shows the

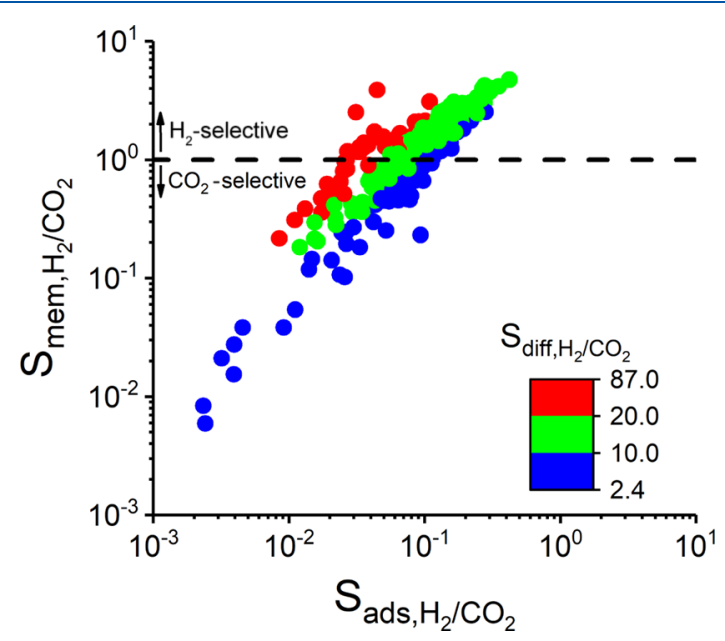

Figure 4. Comparison of adsorption, diffusion, and membrane selectivities of COFs computed at 10 bar and $298 \mathrm{~K}$. The black dashed line symbolizes that $S_{\mathrm{mem}, \mathrm{H}_{2} / \mathrm{CO}_{2}}$ is equal to 1 . Red, green, and blue data points represent COF membranes offering high, moderate, and low $\mathrm{H}_{2} / \mathrm{CO}_{2}$ diffusion selectivities, respectively.

relations between adsorption, diffusion, and membrane selectivities of COFs. The adsorption selectivities for $\mathrm{H}_{2}$ $\left(S_{\text {ads, } \mathrm{H}_{2} / \mathrm{CO}_{2}}\right)$ were found to be lower than unity (between 2.3 $\times 10^{-3}$ and 0.42 ) because of the stronger affinity of COFs to $\mathrm{CO}_{2}$ than to $\mathrm{H}_{2}$. On the other hand, weakly adsorbed and light $\mathrm{H}_{2}$ molecules diffuse faster than $\mathrm{CO}_{2}$ through $\mathrm{COF}$ membranes, resulting in $\mathrm{H}_{2}$ diffusion selectivities $\left(S_{\text {diff, } \mathrm{H}_{2} / \mathrm{CO}_{2}}\right)$ higher than unity, in the range of 2.4-86.9. Figure 4 shows that $88 \mathrm{COFs}$ having $\mathrm{H}_{2} / \mathrm{CO}_{2}$ adsorption selectivities between 0.03 and 0.42 became $\mathrm{H}_{2}$-selective membranes $\left(\mathrm{S}_{\mathrm{mem}, \mathrm{H}_{2} / \mathrm{CO}_{2}}>\right.$ 2) because of their high $\mathrm{H}_{2} / \mathrm{CO}_{2}$ diffusion selectivities (986.9). For these COFs, $\mathrm{H}_{2}$ diffusion selectivity dominated adsorption selectivity. When we examined $20 \mathrm{COF}$ membranes offering the highest $S_{\mathrm{mem}, \mathrm{H}_{2} / \mathrm{CO}_{2}}$ (in the range of 3.07-4.74), 19 of them have $S_{\mathrm{diff}, \mathrm{H}_{2} / \mathrm{CO}_{2}}$ in the range of 11.3-18.7. Although it has a moderate $S_{\mathrm{diff}_{2} / \mathrm{HO}_{2}}(11.3)$, CCOF-2 ${ }^{95}$ has the highest $S_{\text {mem, } \mathrm{H}_{2} / \mathrm{CO}_{2}}(4.74)$ among all COFs. The main factor is that it has the highest $S_{\mathrm{ads}, \mathrm{H}_{2} / \mathrm{CO}_{2}}(0.42)$ because the large pores (an
LCD of $22.90 \AA$ ) allow the passage and adsorption of both molecules. COF-LZU8 has the highest $S_{\text {diff, } \mathrm{H}_{2} / \mathrm{CO}_{2}}$ (86.9) among all COF membranes. It can be attributed to its functional groups ${ }^{96}$ which probably hinder the diffusion of $\mathrm{CO}_{2}$ molecules and favor the diffusion of $\mathrm{H}_{2}$ molecules. Low $\mathrm{S}_{\mathrm{ads}, \mathrm{H}_{2} / \mathrm{CO}_{2}}$ of COF-LZU8 led to an $S_{\mathrm{mem}, \mathrm{H}_{2} / \mathrm{CO}_{2}}$ (3.88) slightly lower than that of CCOF-2. A total of $82 \mathrm{COF}$ membranes exhibited a nonselective behavior because their $S_{\mathrm{mem}, \mathrm{H}_{2} / \mathrm{CO}_{2}}$ values were found in the range of 0.7-1.5, and neither $S_{\text {ads }, \mathrm{H}_{2} / \mathrm{CO}_{2}}$ nor $S_{\text {diff, } \mathrm{H}_{2} / \mathrm{CO}_{2}}$ led to high $S_{\text {mem }, \mathrm{H}_{2} / \mathrm{CO}_{2}}$ for these COFs. Usage of these COFs as adsorbents is more appropriate as they have good $S_{\mathrm{ads}, \mathrm{CO}_{2} / \mathrm{H}_{2}}$ values, up to $\sim 40$. Another result of Figure 4 is that $9 \mathrm{COFs}$ with the highest $\mathrm{CO}_{2}$ adsorption selectivities $\left(S_{\mathrm{ads}, \mathrm{CO}_{2} / \mathrm{H}_{2}}>90\right)$ under PSA and PTSA conditions were identified as $\mathrm{CO}_{2}$-selective membranes $\left(S_{\mathrm{mem}, \mathrm{CO}_{2} / \mathrm{H}_{2}}>3\right)$. The $\mathrm{CO}_{2}$ uptake and $S_{\text {ads, } \mathrm{CO}_{2} / \mathrm{H}_{2}}$ of these COFs were computed in the range of $1.77-6.64 \mathrm{~mol} / \mathrm{kg}$ and $90-428$ at $10 \mathrm{bar}$ and $298 \mathrm{~K}$, respectively. High $\mathrm{CO}_{2}$ uptake in the pores of COFs causes steric hindrance and blocks the passage of $\mathrm{H}_{2}$ molecules through pores because these COFs have narrow pore sizes (4.11-14.93 $\AA$ ). As a result, these COFs have limited $S_{\text {diff, } \mathrm{H}_{2} / \mathrm{CO}_{2}}$, and they act as $\mathrm{CO}_{2}$-selective membranes.

Figure 5 shows the relation between $\mathrm{H}_{2}$ selectivity and permeability of COF membranes. Robeson's upper bound ${ }^{17}$ is

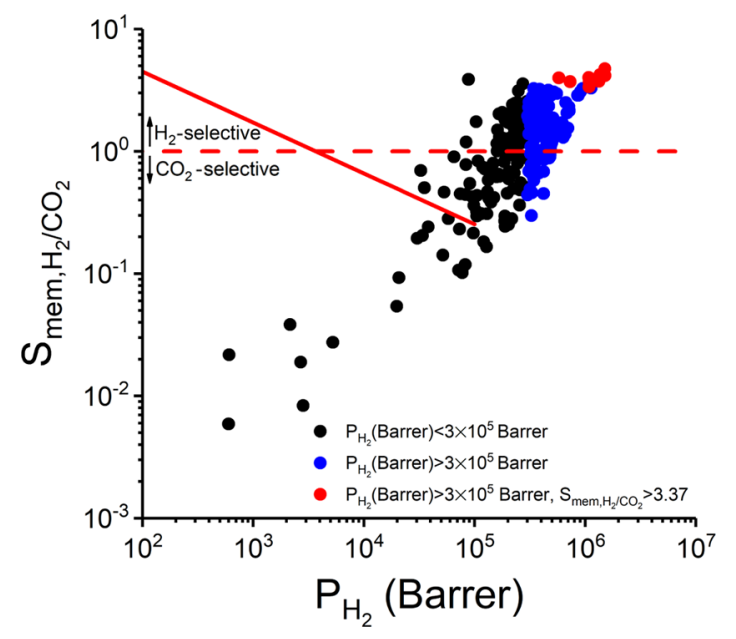

Figure 5. Relationship between $\mathrm{H}_{2} / \mathrm{CO}_{2}$ membrane selectivity and $\mathrm{H}_{2}$ permeability of COF membranes. The red dashed line symbolizes that $S_{\text {mem, } \mathrm{H}_{2} / \mathrm{CO}_{2}}$ is equal to 1 , whereas the red solid line indicates the Robeson upper bound for $\mathrm{H}_{2} / \mathrm{CO}_{2}$ separation.

also depicted to compare the separation performances of COF membranes with polymeric membranes. The $S_{\mathrm{mem}, \mathrm{H}_{2} / \mathrm{CO}_{2}}$ values of COFs were calculated in the range of $5.91 \times 10^{-3}$ to 4.74 , and their $\mathrm{H}_{2}$ permeabilities were computed to range from 599 to $1.5 \times 10^{6}$ barrer. The $S_{\mathrm{mem}, \mathrm{H}_{2} / \mathrm{CO}_{2}}$ and $P_{\mathrm{H}_{2}}$ values of $\mathrm{MOF}$ membranes were previously reported in the ranges of $2 \times 10^{-5}$ to 6.34 and 229 to $1.7 \times 10^{6}$ barrer, respectively, under infinite dilution conditions. ${ }^{55}$ Although conditions are different since we studied separation of the $\mathrm{H}_{2} / \mathrm{CO}_{2}$ mixture at a practical pressure in this work, a comparison of COF membranes with MOFs showed that they have similar performances. Compared to the membrane-based separation performances of polymers $\left(S_{\mathrm{mem}, \mathrm{H}_{2} / \mathrm{CO}_{2}}: 0.1-99.6, P_{\mathrm{H}_{2}}: 4.57 \times 10^{-2}\right.$ to $2.26 \times 10^{4}$ barrer $)$, 

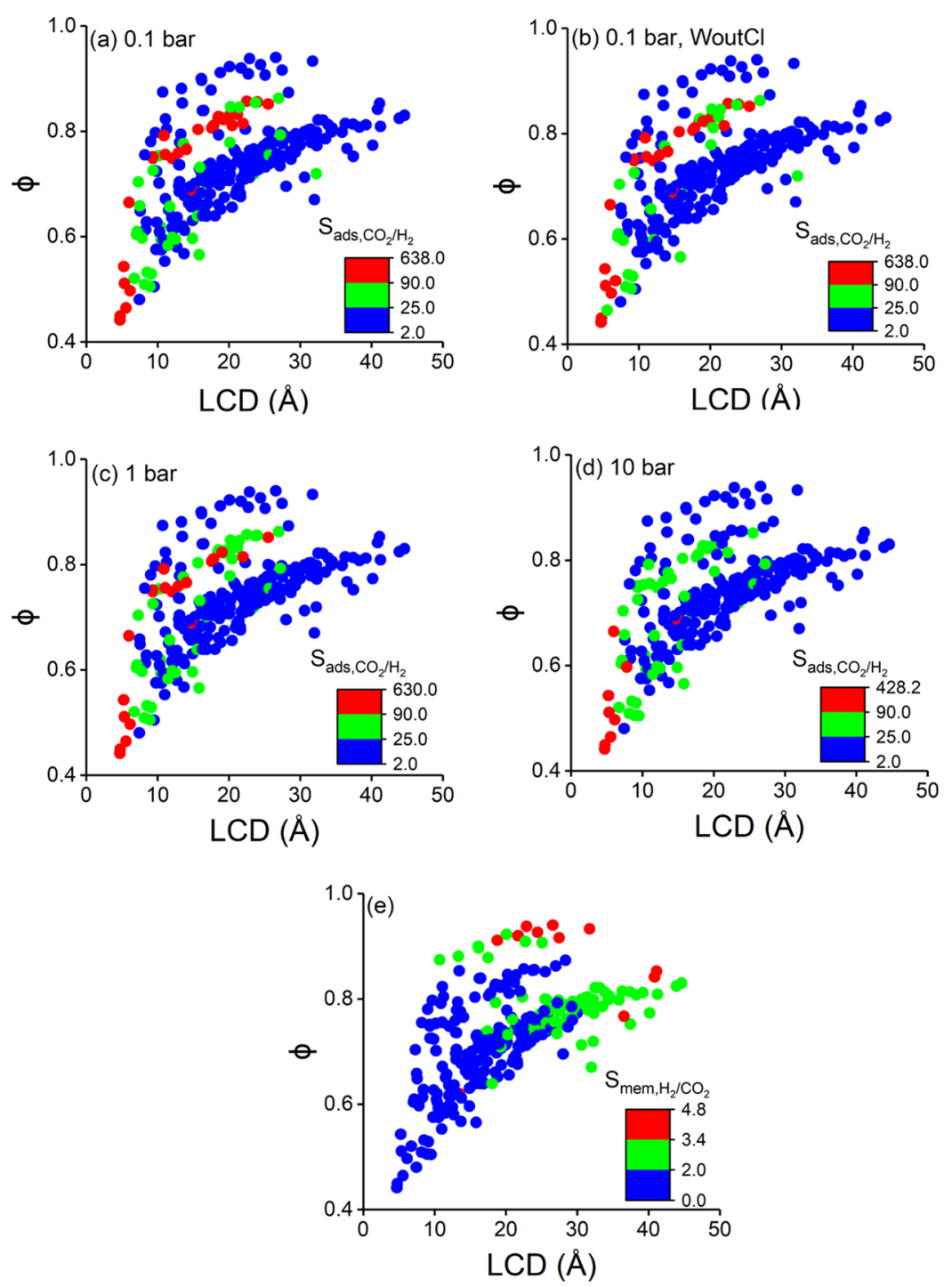

Figure 6. Relationship between porosities, pore sizes, and $\mathrm{CO}_{2} / \mathrm{H}_{2}$ adsorption selectivities of COFs at (a) 0.1 bar, (b) 0.1 bar without Coulomb interactions (WoutCl), (c) 1 bar, and (d) 10 bar at $298 \mathrm{~K}$. (e) Relation between porosities $(\phi)$, LCDs, and $\mathrm{H}_{2} / \mathrm{CO}_{2}$ membrane selectivities $\left(\mathrm{S}_{\mathrm{mem}, \mathrm{H}_{2} / \mathrm{CO}_{2}}\right)$ of COFs. Blue, green, and red points symbolize COFs with low, moderate, and high selectivities, respectively.

COFs have a narrower range of $S_{\mathrm{mem}, \mathrm{H}_{2} / \mathrm{CO}_{2}}$ values but much higher $P_{\mathrm{H}_{2}}$ values. Almost all COFs, 268 out of 288, surpass Robeson's upper bound, suggesting that $\mathrm{COF}$ membranes can perform better than polymeric membranes for $\mathrm{H}_{2} / \mathrm{CO}_{2}$ separation. COF membranes also have better performances than various zeolite membranes ( $\mathrm{NaX}, \mathrm{NaY}, \mathrm{TON}, \mathrm{MFI}, \mathrm{CHA}$, DDR, ERI, and TSC) which have an $S_{\text {mem }, \mathrm{H}_{2} / \mathrm{CO}_{2}}$ of $0.02-1.02$ and a $P_{\mathrm{H}_{2}}$ in the range of $2.26 \times 10^{3}-4.19 \times 10^{4}$ barrer at 10 bar and $300 \mathrm{~K}^{77} \mathrm{~A}$ total of $146 \mathrm{COF}$ shown by blue in Figure 5 had high permeabilities $\left(P_{\mathrm{H}_{2}}>3 \times 10^{5}\right.$ barrer $)$, and the top $10 \mathrm{COF}$ membranes were selected to have $P_{\mathrm{H}_{2}}>3 \times 10^{5}$ barrer with the highest $S_{\mathrm{mem}, \mathrm{H}_{2} / \mathrm{CO}_{2}}$ values as shown with red symbols. Structural features (LCD, PLD, $\phi$, and $S_{\text {acc }}$ ) and adsorption, diffusion, and membrane selectivities of the top $10 \mathrm{COF}$ membranes are listed in Table S8. All top COF membranes have low $\mathrm{CO}_{2}$ adsorption selectivities $(<5)$ and mediocre $\mathrm{H}_{2}$ diffusion selectivities $(11-15)$. This is expected because adsorption favors $\mathrm{CO}_{2}$, while diffusion favors $\mathrm{H}_{2}$. To obtain high $P_{\mathrm{H}_{2}}$ and $\mathrm{S}_{\text {mem, } \mathrm{H}_{2} / \mathrm{CO}_{2}}, \mathrm{H}_{2}$ diffusion selectivities should dominate the $\mathrm{CO}_{2}$ adsorption selectivities. We also note that the most promising COF membranes generally have large pores (LCDs and PLDs $>20 \AA)$ and very porous structures $(\phi$ $>0.85)$, as discussed in detail below.

3.3. Structure-Performance Relations. The analyses relating structural features to performance metrics help us to reveal which adsorbents/membranes tend to have exceptional performances according to structural parameters and also give molecular insight to experimentalists for synthesizing efficient materials. Therefore, we investigated the relationships between selectivities of COF adsorbents/membranes and their structural properties, $\phi$ and LCD. We would like to note that all COF structures were assumed to be rigid and stable in the form that was obtained from the database. At low pressure, highly selective COF adsorbents $\left(S_{\mathrm{ads}, \mathrm{CO}_{2} / \mathrm{H}_{2}}>90\right)$ have a large range of pore sizes $(4 \AA<\mathrm{LCD}<25 \AA)$ and porosities $(0.44<$ $\phi<0.86)$ as shown in Figure 6a. Because COFs that we examined have larger pores than the size of $\mathrm{CO}_{2}$ and $\mathrm{H}_{2}$, we did not observe any molecular sieving effect. The $\mathrm{CO}_{2} / \mathrm{H}_{2}$ selectivities of COFs are mainly determined by the interactions of gas molecules with the adsorption sites of COFs at low 
pressures rather than the structural features. Contribution of $\mathrm{CO}_{2}-\mathrm{COF}$ electrostatic interactions to selectivities was also shown at low pressure, as shown in Figure $6 \mathrm{~b}$, by switching off the electrostatic interactions between $\mathrm{CO}_{2}$ and the COF. $S_{\mathrm{ads}, \mathrm{CO}_{2} / \mathrm{H}_{2}}$ of 6 (15) COFs dropped from the range of 90-638 (25-90) to the range of 25-90 (2-25). Although the Coulombic interactions are important especially for some of the highly selective COFs, van der Waals interactions between $\mathrm{COF}$ atoms and gases are the main factor that determines $S_{\text {ads }, \mathrm{CO}_{2} / \mathrm{H}_{2}}$ of most COFs at low pressures. For example, the contribution of van der Waals interactions to host-adsorbate energy is $>90 \%$ for the majority of COFs (196 among 288 COFs) at 0.1 bar. Because $\mathrm{CO}_{2}$ molecules have three interaction sites, they adsorb more strongly in COFs than $\mathrm{H}_{2}$ molecules which are modeled as single-site molecules. This results in $\mathrm{CO}_{2}$-selective COFs regardless of their pore sizes and porosities at 0.1 bar.

Figure $6 \mathrm{c}$,d shows how $S_{\mathrm{ads}, \mathrm{CO}_{2} / \mathrm{H}_{2}}$ changes with respect to LCD and $\phi$ at 1 and 10 bar. A significant result is that the number of COFs with high $S_{\mathrm{ads}, \mathrm{CO}_{2} / \mathrm{H}_{2}}$ at 1 and 10 bar is lower compared to that at 0.1 bar. When pressure increases, adsorbed $\mathrm{H}_{2}$ molecules increase more than the increase in the adsorbed $\mathrm{CO}_{2}$ molecules in pores; therefore, lower $S_{\mathrm{ads}, \mathrm{CO}_{2} / \mathrm{H}_{2}}$ values are obtained at 1 and 10 bar compared to 0.1 bar. COFs with high $S_{\text {ads, } \mathrm{CO}_{2} / \mathrm{H}_{2}}$ at 10 bar generally have narrow pores ( $\left.\mathrm{LCD}<10 \AA\right)$ and low porosities $(\phi<0.65)$. This is because COFs with large pores provide more adsorption space available for both gases, whereas in COFs with narrow pores, $\mathrm{CO}_{2}$ molecules can dominate the available adsorption sites. To get a better understanding of the pressure effect on the $\mathrm{CO}_{2}$ and $\mathrm{H}_{2}$ adsorption, we performed GCMC simulations at an additional pressure ( 5 bar) and different temperatures (338 and $423 \mathrm{~K}$ ). The $S_{\mathrm{ads}, \mathrm{CO}_{2} / \mathrm{H}_{2}}$ values were computed for each temperaturepressure combination, and the results are shown in Figure S6. The highest number of COFs having $S_{\mathrm{ads}, \mathrm{CO}_{2} / \mathrm{H}_{2}}>100$ was obtained at $0.1 \mathrm{bar}$ and $298 \mathrm{~K}$. When the pressure was increased from 0.1 to 1 bar or from 1 to 10 bar at a constant temperature, the $S_{\mathrm{ads}, \mathrm{CO}_{2} / \mathrm{H}_{2}}$ values dropped. When the pressure was constant and the temperature was increased, low $S_{\mathrm{ads}, \mathrm{CO}_{2} / \mathrm{H}_{2}}$ values were obtained, and the effect of pressure on the selectivities was found to be negligible at high temperatures $(>298 \mathrm{~K})$. As a result, COFs have high $S_{\mathrm{ads}, \mathrm{CO}_{2} / \mathrm{H}_{2}}$ at low pressures and low temperatures.

Apart from computable structural properties, heat of adsorption $\left(Q_{\mathrm{st}}\right)$ is also known to be important in determining the gas separation performances of materials. Yang et al. ${ }^{97}$ proposed an equation, $\ln S=-0.8558+\Delta Q_{\mathrm{st}}^{0} /(R \times T)$, to relate adsorption selectivity to the heats of adsorption at infinite dilution. Here, $S$ is the selectivity, $\Delta Q_{s t}^{0}$ represents the difference between isosteric heats of adsorption of gases at infinite dilution, $R$ is the ideal gas constant, and $T$ is the temperature. Motivated from this model, we showed the relation between our simulated $S_{\mathrm{ads}, \mathrm{CO}_{2} / \mathrm{H}_{2}}$ and $\Delta Q_{\mathrm{st}}^{0}$ values, as shown in Figure S7, where Yang's model was demonstrated with a red line. We noticed that the $S_{\mathrm{ads}, \mathrm{CO}_{2} / \mathrm{H}_{2}}$ values of COFs have a wider distribution and they deviate more from the $S$ values of Yang's model at 1 and 10 bar compared to those at 0.1 bar. This is expected because the model is based on the pore-gas interactions at infinite dilution, and at high pressures, gas-gas interactions play an important role on the adsorption selectivity. Another important pattern is that the agreement between $S_{\mathrm{ads}, \mathrm{CO}_{2} / \mathrm{H}_{2}}$ and $S$ values was good/moderate when $\Delta Q_{\text {st }}^{0} \leq 15 \mathrm{~kJ} / \mathrm{mol}$ at all pressures, but $S$ significantly overestimated the $S_{\mathrm{ads}, \mathrm{CO}_{2} / \mathrm{H}_{2}}$ values of COFs for which $\Delta Q_{\mathrm{st}}^{0}$ $>15 \mathrm{~kJ} / \mathrm{mol}$. Overall, for the COFs with $\Delta Q_{\mathrm{st}}^{0} \leq 15 \mathrm{~kJ} / \mathrm{mol}$, the model can accurately predict selectivities, at $0.1,1$, and 10 bar.

To better understand the correlation between $\Delta Q_{\mathrm{st}}^{0}$ and pore properties of COFs, we also investigated the relationship between pore sizes and $\Delta Q_{s t}^{0}$ as shown in Figure S8, which was colored according to $S_{\mathrm{ads}, \mathrm{CO}_{2} / \mathrm{H}_{2}}$. The $\Delta Q_{\mathrm{st}}^{0}$ values of COFs were computed in the range of $4.7-29.4 \mathrm{~kJ} / \mathrm{mol}$. As expected, COFs with small pores (LCD $<15 \AA$ ) have high $\Delta Q_{\text {st }}^{0}$ values. This trend was previously reported for $\mathrm{H}_{2}$ storage of MOFs in the literature. ${ }^{98}$ However, in Figure S8, there are many highly selective COFs with large pores and with $\Delta Q_{\mathrm{st}}^{0}>15 \mathrm{~kJ} / \mathrm{mol}$, especially at 0.1 bar. We examined these COFs in more detail to understand what causes the high $\Delta Q_{\mathrm{st}}^{0}$ values. For instance, CPF-group $\mathrm{COFs}^{99}$ were computed to have a $\Delta Q_{\mathrm{st}}^{0}$ of $26 \mathrm{~kJ} /$ mol, although they have large pores (LCD > $20 \AA$ ). This group of COFs include porphyrin subunits, and it was reported in the literature that these groups favor the $\mathrm{CO}_{2}$ adsorption. ${ }^{100} \mathrm{We}$ realized that several of the COFs with high $S_{\text {ads, } \mathrm{CO}_{2} / \mathrm{H}_{2}}, \Delta Q_{\mathrm{st}}^{0} \geq$ $15 \mathrm{~kJ} / \mathrm{mol}$, and large pores (LCD > $15 \AA$ ) also have porphyrin subunits. $^{86,101,102}$ Therefore, high $\Delta Q_{\mathrm{st}}^{0}$ of these large-pored COFs can be attributed to the existence of subunits favoring adsorption of $\mathrm{CO}_{2}$ such as porphyrins. As Yang's model correlates the selectivity of adsorbents to the pore size and confinement of the gas molecule in the pores at infinite dilution, it deviates for materials with specific interactions such as the ones having strong electrostatic interactions. ${ }^{97}$ Therefore, overestimation of the selectivities of some COFs by the model can be attributed to the existence of specific sites that lead to strong adsorption of $\mathrm{CO}_{2}$ molecules.

Finally, structure-performance relations of COF membranes were studied. The relationship between LCD, $\phi$, and $S_{\mathrm{mem}, \mathrm{H}_{2} / \mathrm{CO}_{2}}$ of COFs, which was computed for the $\mathrm{H}_{2} / \mathrm{CO}_{2}$ : $85 / 15$ mixture, is illustrated in Figure 6e. $\mathrm{H}_{2}$-selective $\mathrm{COF}$ membranes mostly have PLDs and LCDs $>20 \AA$ and $\phi>0.8$. As mentioned before in the discussion of Figure $6 \mathrm{~d}$, we observed that COFs with narrow pores and low porosities tend to become $\mathrm{CO}_{2}$-selective materials. $\mathrm{CO}_{2}$ molecules were more strongly confined into the narrow pores, and they block the passage of $\mathrm{H}_{2}$ molecules. Therefore, low $\mathrm{H}_{2} / \mathrm{CO}_{2}$ membrane selectivities were obtained for these COFs at 10 bar and $298 \mathrm{~K}$. We also observed that COFs consisting of large pores (LCD > $20 \AA$ ) and having highly porous $(\phi>0.8)$ structures usually have low $S_{\text {ads, } \mathrm{CO}_{2} / \mathrm{H}_{2}}(<25)$ at 10 bar and $298 \mathrm{~K}$ as both gas molecules can easily adsorb. As a result, $\mathrm{H}_{2}$ diffusion dominates $\mathrm{CO}_{2}$ adsorption in these COFs and COFs with highly porous structures tend to be $\mathrm{H}_{2}$-selective membranes.

\section{CONCLUSIONS}

In this work, we uncovered the $\mathrm{CO}_{2} / \mathrm{H}_{2}$ mixture separation performances of $288 \mathrm{COFs}$ using a high-throughput computational screening approach for several different adsorptionbased processes, VSA, PSA, TSA, VTSA, and PTSA. We showed that while VSA, TSA, and VTSA are attractive processes in terms of offering high adsorption selectivities, the PSA and PTSA processes offer higher working capacities for 
$\mathrm{CO}_{2} / \mathrm{H}_{2}$ separation. Considering the combination of these performance metrics of COFs, the highest APSs accompanied with high $R \%$ values for COF adsorbents were obtained under PTSA conditions, revealing the effectiveness of combining pressure and temperature swing for adsorption-based $\mathrm{CO}_{2}$ separation processes. Many COFs were found to have higher adsorption selectivities (2.4-428) and working capacities $(0.21-6.82 \mathrm{~mol} / \mathrm{kg})$ compared to zeolites, indicating that COFs can replace traditional porous materials in adsorptionbased $\mathrm{CO}_{2} / \mathrm{H}_{2}$ mixture separation. Structure-performance relations revealed that COFs with low porosities $(\phi<0.65)$ and narrow pores (LCD $<10 \AA$ ) lead to high $S_{\mathrm{ads}, \mathrm{CO}_{2} / \mathrm{H}_{2}}$ because these structural features enhance the confinement of $\mathrm{CO}_{2}$ molecules. We also examined membrane-based $\mathrm{CO}_{2} / \mathrm{H}_{2}$ mixture separation performances of $288 \mathrm{COFs}$ at $10 \mathrm{bar}$ and $298 \mathrm{~K}$, and the majority of COF membranes (268) exceeded Robeson's upper bound because of their higher $P_{\mathrm{H}_{2}}$ (599 to $1.51 \times 10^{6}$ barrer) than the conventional polymer membranes. Promising COF membranes for selective separation of $\mathrm{H}_{2}$ from $\mathrm{CO}_{2}$ were computed to have high porosities $(\phi>0.85)$ and large pores $(\mathrm{LCD}>20 \AA)$. These results indicated that COFs are strong candidates to replace zeolites as adsorbents and to replace polymers as membranes for $\mathrm{CO}_{2} / \mathrm{H}_{2}$ separation. As a newly emerged material group, $\mathrm{COFs}$ are on the verge of becoming promising options for precombustion $\mathrm{CO}_{2}$ capture, and the results of this high-throughput computational screening study will complement the experimental efforts for selecting the best COFs for adsorption and membrane-based $\mathrm{CO}_{2} / \mathrm{H}_{2}$ separation.

\section{ASSOCIATED CONTENT}

\section{SI Supporting Information}

The Supporting Information is available free of charge at https://pubs.acs.org/doi/10.1021/acs.jpcc.0c07062.

Flowchart diagram of the screening procedure for COF sets; comparison of experimental data and simulation results for single-component adsorption isotherms of $\mathrm{CO}_{2}$ for COFs; $\mathrm{R} \%$-APS relations of COFs; adsorption selectivities of COFs with and without the Coulomb interactions; snapshots of EB-COF:F with adsorbed $\mathrm{CO}_{2}$ and $\mathrm{H}_{2}$ molecules; comparison of $\mathrm{CO}_{2}$ adsorption uptakes and $R \%$ for the VSA and TSA processes; comparison of adsorption selectivities under different conditions; relation between isosteric heats of adsorption and $\mathrm{CO}_{2} / \mathrm{H}_{2}$ adsorption selectivities of COFs; relation between pore sizes and isosteric heats of adsorption of COFs; lists of the top-performing COFs; and correlation coefficients for the performance evaluation metrics (PDF)

\section{AUTHOR INFORMATION}

\section{Corresponding Author}

Seda Keskin - Department of Chemical and Biological Engineering, Koc University, 34450 Istanbul, Turkey; ○ orcid.org/0000-0001-5968-0336; Phone: +90 (212) 3381362; Email: skeskin@ku.edu.tr

\section{Authors}

Gokhan Onder Aksu - Department of Chemical and Biological Engineering, Koc University, 34450 Istanbul, Turkey

Hilal Daglar - Department of Chemical and Biological Engineering, Koc University, 34450 Istanbul, Turkey
Cigdem Altintas - Department of Chemical and Biological Engineering, Koc University, 34450 Istanbul, Turkey

Complete contact information is available at:

https://pubs.acs.org/10.1021/acs.jpcc.0c07062

\section{Notes}

The authors declare no competing financial interest.

\section{ACKNOWLEDGMENTS}

S.K. acknowledges ERC-2017-Starting Grant. This study has received funding from the European Research Council (ERC) under the European Union's Horizon 2020 research and innovation programme (ERC-2017-Starting Grant, grant agreement no. 756489-COSMOS).

\section{REFERENCES}

(1) Zito, P. F.; Caravella, A.; Brunetti, A.; Drioli, E.; Barbieri, G. $\mathrm{CO}_{2} / \mathrm{H}_{2}$ Selectivity Prediction of $\mathrm{NaY}, \mathrm{DD} 3 \mathrm{R}$, and Silicalite Zeolite Membranes. Ind. Eng. Chem. Res. 2018, 57, 11431-11438.

(2) Theo, W. L.; Lim, J. S.; Hashim, H.; Mustaffa, A. A.; Ho, W. S. Review of Pre-Combustion Capture and Ionic Liquid in Carbon Capture and Storage. Appl. Energy 2016, 183, 1633-1663.

(3) Davison, J.; Arienti, S.; Cotone, P.; Mancuso, L. Co-Production of Hydrogen and Electricity with $\mathrm{CO}_{2}$ Capture. Int. J. Greenhouse Gas Control 2010, 4, 125-130.

(4) Kenarsari, S. D.; Yang, D.; Jiang, G.; Zhang, S.; Wang, J.; Russell, A. G.; Wei, Q.; Fan, M. Review of Recent Advances in Carbon Dioxide Separation and Capture. RSC Adv. 2013, 3, 22739-22773.

(5) Mason, J. A.; Sumida, K.; Herm, Z. R.; Krishna, R.; Long, J. R. Evaluating Metal-Organic Frameworks for Post-Combustion Carbon Dioxide Capture via Temperature Swing Adsorption. Energy Environ. Sci. 2011, 4, 3030-3040.

(6) Sircar, S.; Golden, T. C. Purification of Hydrogen by Pressure Swing Adsorption. Sep. Sci. Technol. 2000, 35, 667-687.

(7) Ben-Mansour, R.; Qasem, N. A. A. Management An Efficient Temperature Swing Adsorption (TSA) Process for Separating $\mathrm{CO}_{2}$ from $\mathrm{CO}_{2} / \mathrm{N}_{2}$ Mixture Using Mg-MOF-74. Energy Convers. Manag. 2018, 156, 10-24.

(8) García, S.; Gil, M. V.; Pis, J. J.; Rubiera, F.; Pevida, C. Cyclic Operation of a Fixed-Bed Pressure and Temperature Swing Process for $\mathrm{CO}_{2}$ Capture: Experimental and Statistical Analysis. Int. J. Greenhouse Gas Control 2013, 12, 35-43.

(9) Xiao, P.; Wilson, S.; Xiao, G.; Singh, R.; Webley, P. Novel Adsorption Processes for Carbon Dioxide Capture within a IGCC Process. Energy Procedia 2009, 1, 631-638.

(10) Wang, L.; Liu, Z.; Li, P.; Yu, J.; Rodrigues, A. E. Experimental and Modeling Investigation on Post-Combustion Carbon Dioxide Capture Using Zeolite 13X-APG by Hybrid VTSA Process. Chem. Eng. J. 2012, 197, 151-161.

(11) Hufton, J. R.; Mayorga, S.; Sircar, S. Sorption-Enhanced Reaction Process for Hydrogen Production. AIChE J. 1999, 45, 248256.

(12) Kamakoti, P.; Leta, D. P.; Deckman, H. W.; Ravikovitch, P. I.; Anderson, T. N. Pressure-Temperature Swing Adsorption Process. U.S. Patent 8,784,534B2, 2014.

(13) Yu, J.; Xie, L.-H.; Li, J.-R.; Ma, Y.; Seminario, J. M.; Balbuena, P. B. $\mathrm{CO}_{2}$ Capture and Separations Using MOFs: Computational and Experimental Studies. Chem. Rev. 2017, 117, 9674-9754.

(14) Scholes, C. A.; Smith, K. H.; Kentish, S. E.; Stevens, G. W. $\mathrm{CO}_{2}$ Capture from Pre-Combustion Processes-Strategies for Membrane Gas Separation. Int. J. Greenhouse Gas Control 2010, 4, 739-755.

(15) Yampolskii, Y. Polymeric Gas Separation Membranes. Macromolecules 2012, 45, 3298-3311.

(16) Sanders, D. F.; Smith, Z. P.; Guo, R.; Robeson, L. M.; McGrath, J. E.; Paul, D. R.; Freeman, B. D. Energy-Efficient Polymeric Gas Separation Membranes for a Sustainable Future: A Review. Polymer 2013, 54, 4729-4761. 
(17) Robeson, L. M. The Upper Bound Revisited. J. Membr. Sci. 2008, 320, 390-400.

(18) Korelskiy, D.; Ye, P.; Fouladvand, S.; Karimi, S.; Sjöberg, E.; Hedlund, J. Efficient Ceramic Zeolite Membranes for $\mathrm{CO}_{2} / \mathrm{H}_{2}$ Separation. J. Mater. Chem. A 2015, 3, 12500-12506.

(19) Caro, J.; Noack, M. Zeolite Membranes-Status and Prospective. Advances in Nanoporous Materials; Elsevier: Oxford, 2010; Vol. 1, pp 1-96.

(20) Li, J.-R.; Sculley, J.; Zhou, H.-C. Metal-Organic Frameworks for Separations. Chem. Rev. 2012, 112, 869-932.

(21) Kang, Z.; Fan, L.; Sun, D. Recent Advances and Challenges of Metal-Organic Framework Membranes for Gas Separation. J. Mater. Chem. A 2017, 5, 10073-10091.

(22) Banerjee, D.; Simon, C. M.; Plonka, A. M.; Motkuri, R. K.; Liu, J.; Chen, X.; Smit, B.; Parise, J. B.; Haranczyk, M.; Thallapally, P. K. Metal-Organic Framework with Optimally Selective Xenon Adsorption and Separation. Nat. Commun. 2016, 7, 11831.

(23) Lin, R.-B.; Li, L.; Zhou, H.-L.; Wu, H.; He, C.; Li, S.; Krishna, R.; Li, J.; Zhou, W.; Chen, B. Molecular Sieving of Ethylene from Ethane Using a Rigid Metal-Organic Framework. Nat. Mater. 2018, $17,1128-1133$.

(24) Cote, A. P.; Benin, A. I.; Ockwig, N. W.; O’Keeffe, M.; Matzger, A. J.; Yaghi, O. M. Porous, Crystalline, Covalent Organic Frameworks. Science 2005, 310, 1166-1170.

(25) El-Kaderi, H. M.; Hunt, J. R.; Mendoza-Cortes, J. L.; Cote, A. P.; Taylor, R. E.; O'Keeffe, M.; Yaghi, O. M. Designed Synthesis of 3D Covalent Organic Frameworks. Science 2007, 316, 268-272.

(26) Zeng, Y.; Zou, R.; Zhao, Y. Covalent Organic Frameworks for $\mathrm{CO}_{2}$ Capture. Adv. Mater. 2016, 28, 2855-2873.

(27) Furukawa, H.; Yaghi, O. M. Storage of Hydrogen, Methane, and Carbon Dioxide in Highly Porous Covalent Organic Frameworks for Clean Energy Applications. J. Am. Chem. Soc. 2009, 131, 88758883.

(28) Yu, J.-T.; Chen, Z.; Sun, J.; Huang, Z.-T.; Zheng, Q.-Y. Cyclotricatechylene Based Porous Crystalline Material: Synthesis and Applications in Gas Storage. J. Mater. Chem. 2012, 22, 5369-5373.

(29) Li, Y.; Yang, R. T. Hydrogen Storage in Metal-Organic and Covalent-Organic Frameworks by Spillover. AIChE J. 2008, 54, 269279.

(30) Rabbani, M. G.; Sekizkardes, A. K.; Kahveci, Z.; Reich, T. E.; Ding, R.; El-Kaderi, H. M. A 2D Mesoporous Imine-Linked Covalent Organic Framework for High Pressure Gas Storage Applications. Chem.-Eur. J. 2013, 19, 3324-3328.

(31) Han, S. S.; Furukawa, H.; Yaghi, O. M.; Goddard, W. A. Covalent Organic Frameworks as Exceptional Hydrogen Storage Materials. J. Am. Chem. Soc. 2008, 130, 11580-11581.

(32) Garberoglio, G. Computer Simulation of the Adsorption of Light Gases in Covalent Organic Frameworks. Langmuir 2007, 23, 12154-12158.

(33) Keskin, S. Adsorption, Diffusion, and Separation of $\mathrm{CH}_{4} / \mathrm{H}_{2}$ Mixtures in Covalent Organic Frameworks: Molecular Simulations and Theoretical Predictions. J. Phys. Chem. C 2012, 116, 1772-1779.

(34) Babarao, R.; Jiang, J. Exceptionally High $\mathrm{CO}_{2}$ Storage in Covalent-Organic Frameworks: Atomistic Simulation Study. Energy Environ. Sci. 2008, 1, 139-143.

(35) Yang, Q.; Zhong, C. Molecular Simulation Study of the Stepped Behaviors of Gas Adsorption in Two-Dimensional Covalent Organic Frameworks. Langmuir 2009, 25, 2302-2308.

(36) Zhang, M.; Zheng, R.; Ma, Y.; Chen, R.; Sun, X.; Sun, X. NRich Covalent Organic Frameworks with Different Pore Size for High-Pressure $\mathrm{CO}_{2}$ Adsorption. Microporous Mesoporous Mater. 2019, $285,70-79$.

(37) Zeng, H.; Liu, Y.; Liu, H. Adsorption and Diffusion of $\mathrm{CO}_{2}$ and $\mathrm{CH}_{4}$ in Covalent Organic Frameworks: an MC/MD Simulation Study. Mol. Simul. 2018, 44, 1244-1251.

(38) Wang, L.; Dong, B.; Ge, R.; Jiang, F.; Xiong, J.; Gao, Y.; Xu, J. A Thiadiazole-Functionalized Covalent Organic Framework for Efficient $\mathrm{CO}_{2}$ Capture and Separation. Microporous Mesoporous Mater. 2016, 224, 95-99.
(39) Liu, Y.; Liu, D.; Yang, Q.; Zhong, C.; Mi, J. Comparative Study of Separation Performance of COFs and MOFs for $\mathrm{CH}_{4} / \mathrm{CO}_{2} / \mathrm{H}_{2}$ Mixtures. Ind. Eng. Chem. Res. 2010, 49, 2902-2906.

(40) Vicent-Luna, J. M.; Luna-Triguero, A.; Calero, S. Storage and Separation of Carbon Dioxide and Methane in Hydrated Covalent Organic Frameworks. J. Phys. Chem. C 2016, 120, 23756-23762.

(41) Ge, Y.; Zhou, H.; Ji, Y.; Ding, L.; Cheng, Y.; Wang, R.; Yang, S.; Liu, Y.; Wu, X.; Li, Y. Understanding Water Adsorption and the Impact on $\mathrm{CO}_{2}$ Capture in Chemically Stable Covalent Organic Frameworks. J. Phys. Chem. C 2018, 122, 27495-27506.

(42) Tong, M.; Yang, Q.; Zhong, C. Computational Screening of Covalent Organic Frameworks for $\mathrm{CH}_{4} / \mathrm{H}_{2}, \mathrm{CO}_{2} / \mathrm{H}_{2}$ and $\mathrm{CO}_{2} / \mathrm{CH}_{4}$ Separations. Microporous Mesoporous Mater. 2015, 210, 142-148.

(43) Krishna, R.; van Baten, J. M. Maxwell-Stefan Modeling of Slowing-Down Effects in Mixed Gas Permeation across Porous Membranes. J. Membr. Sci. 2011, 383, 289-300.

(44) Tong, M.; Zhang, Y.; Yan, T.; Chen, G.; Long, Z.; Qin, Z.; Yang, Q.; Zhong, C. Computational Insights on the Role of Nanochannel Environment in the $\mathrm{CO}_{2} / \mathrm{CH}_{4}$ and $\mathrm{H}_{2} / \mathrm{CH}_{4}$ Separation Using Restacked Covalent Organic Framework Membranes. J. Phys. Chem. C 2019, 123, 22949-22958.

(45) Tong, M.; Lan, Y.; Yang, Q.; Zhong, C. Exploring the Structure-Property Relationships of Covalent Organic Frameworks for Noble Gas Separations. Chem. Eng. Sci. 2017, 168, 456-464.

(46) Tong, M.; Lan, Y.; Qin, Z.; Zhong, C. Computation-Ready, Experimental Covalent Organic Framework for Methane Delivery: Screening and Material Design. J. Phys. Chem. C 2018, 122, 1300913016.

(47) Yan, T.; Lan, Y.; Tong, M.; Zhong, C. Screening and Design of Covalent Organic Framework Membranes for $\mathrm{CO}_{2} / \mathrm{CH}_{4}$ Separation. ACS Sustainable Chem. Eng. 2018, 7, 1220-1227.

(48) Ongari, D.; Yakutovich, A. V.; Talirz, L.; Smit, B. Building a Consistent and Reproducible Database for Adsorption Evaluation in Covalent-Organic Frameworks. ACS Cent. Sci. 2019, 5, 1663-1675.

(49) Gülçay, E.; Findikci, İ. E. Computational Screening of Covalent Organic Frameworks for Hydrogen Storage. J. Turk. Chem. Soc., Sect. A 2020, 7, 65-76.

(50) Gulcay, E.; Erucar, I. Molecular Simulations of COFs, IRMOFs and ZIFs for Adsorption-based Separation of Carbon Tetrachloride from Air. J. Mol. Graphics Modell. 2019, 86, 84-94.

(51) Altundal, O. F.; Altintas, C.; Keskin, S. Can COFs Replace MOFs in Flue Gas Separation? High-Throughput Computational Screening of COFs for $\mathrm{CO}_{2} / \mathrm{N}_{2}$ Separation. J. Mater. Chem. A 2020, 8 , 14609-14623.

(52) Mercado, R.; Fu, R.-S.; Yakutovich, A. V.; Talirz, L.; Haranczyk, M.; Smit, B. In Silico Design of 2D and 3D Covalent Organic Frameworks for Methane Storage Applications. Chem. Mater. 2018, 30, 5069-5086.

(53) Martin, R. L.; Simon, C. M.; Medasani, B.; Britt, D. K.; Smit, B.; Haranczyk, M. In Silico Design of Three-Dimensional Porous Covalent Organic Frameworks via Known Synthesis Routes and Commercially Available Species. J. Phys. Chem. C 2014, 118, 2379023802.

(54) Deeg, K. S.; Damasceno Borges, D.; Ongari, D.; Rampal, N.; Talirz, L.; Yakutovich, A. V.; Huck, J. M.; Smit, B. In Silico Discovery of Covalent Organic Frameworks for Carbon Capture. ACS Appl. Mater. Interfaces 2020, 12, 21559-21568.

(55) Avci, G.; Velioglu, S.; Keskin, S. High-Throughput Screening of MOF Adsorbents and Membranes for $\mathrm{H}_{2}$ Purification and $\mathrm{CO}_{2}$ Capture. ACS Appl. Mater. Interfaces 2018, 10, 33693-33706.

(56) Willems, T. F.; Rycroft, C. H.; Kazi, M.; Meza, J. C.; Haranczyk, M. Algorithms and Tools for High-Throughput Geometry-Based Analysis of Crystalline Porous Materials. Microporous Mesoporous Mater. 2012, 149, 134-141.

(57) Xu, S.-Q.; Liang, R.-R.; Zhan, T.-G.; Qi, Q.-Y.; Zhao, X. Construction of 2D Covalent Organic Frameworks by Taking Advantage of the Variable Orientation of Imine Bonds. Chem. Commun. 2017, 53, 2431-2434. 
(58) Dubbeldam, D.; Calero, S.; Ellis, D. E.; Snurr, R. Q. RASPA: Molecular Simulation Software for Adsorption and Diffusion in Flexible Nanoporous Materials. Mol. Simul. 2016, 42, 81-101.

(59) Lin, S.; Harada, M.; Suzuki, Y.; Hatano, H. Hydrogen Production from Coal by Separating Carbon Dioxide During Gasification. Fuel 2002, 81, 2079-2085.

(60) Buch, V. Path Integral Simulations of Mixed Para-D2 and Ortho-D2 Clusters: The Orientational Effects. J. Chem. Phys. 1994, 100, 7610-7629.

(61) Potoff, J. J.; Siepmann, J. I. Vapor-Liquid Equilibria of Mixtures Containing Alkanes, Carbon Dioxide, and Nitrogen. AIChE J. 2001, $47,1676-1682$

(62) Wilmer, C. E.; Snurr, R. Q. Towards Rapid Computational Screening of Metal-Organic Frameworks for Carbon Dioxide Capture: Calculation of Framework Charges via Charge Equilibration. Chem. Eng. J. 2011, 171, 775-781.

(63) Ewald, P. P. Evaluation of Optical and Electrostatic Lattice Potentials. Ann. Phys. 1921, 369, 253-287.

(64) Frenkel, D.; Smit, B. Understanding Molecular Simulation: From Algorithms to Applications; Elsevier: Amsterdam, 2001; Vol. 1.

(65) Evans, D. J.; Holian, B. L. The Nose-Hoover Thermostat. J. Chem. Phys. 1985, 83, 4069-4074.

(66) Einstein, A. Investigations on the Theory of the Brownian Movement; Courier Corporation: New York, 1956.

(67) Fang, H.; Kulkarni, A.; Kamakoti, P.; Awati, R.; Ravikovitch, P. I.; Sholl, D. S. Identification of High- $\mathrm{CO}_{2}$-Capacity Cationic Zeolites by Accurate. Chem. Mater. 2016, 28, 3887-3896.

(68) Chung, Y. G.; Gómez-Gualdrón, D. A.; Li, P.; Leperi, K. T.; Deria, P.; Zhang, H.; Vermeulen, N. A.; Stoddart, J. F.; You, F.; Hupp, J. T. In Silico Discovery of Metal-Organic Frameworks for Precombustion $\mathrm{CO}_{2}$ Capture Using a Genetic Algorithm. Sci. Adv. 2016, 2, No. e1600909.

(69) Bae, Y.-S.; Snurr, R. Q. Development and Evaluation of Porous Materials for Carbon Dioxide Separation and Capture. Angew. Chem., Int. Ed. 2011, 50, 11586-11596.

(70) Krishna, R.; van Baten, J. M. In Silico Screening of Zeolite Membranes for $\mathrm{CO}_{2}$ Capture. J. Membr. Sci. 2010, 360, 323-333.

(71) Raganati, F.; Chirone, R.; Ammendola, P. $\mathrm{CO}_{2}$ Capture by Temperature Swing Adsorption: Working Capacity as Affected by Temperature and $\mathrm{CO}_{2}$ Partial Pressure. Ind. Eng. Chem. Res. 2020, 59, $3593-3605$.

(72) Gao, Q.; Li, X.; Ning, G.-H.; Xu, H.-S.; Liu, C.; Tian, B.; Tang, W.; Loh, K. P. Covalent Organic Framework with Frustrated Bonding Network for Enhanced Carbon Dioxide Storage. Chem. Mater. 2018, 30, 1762-1768.

(73) Chandra, S.; Kandambeth, S.; Biswal, B. P.; Lukose, B.; Kunjir, S. M.; Chaudhary, M.; Babarao, R.; Heine, T.; Banerjee, R. Chemically Stable Multilayered Covalent Organic Nanosheets from Covalent Organic Frameworks via Mechanical Delamination. J. Am. Chem. Soc. 2013, 135, 17853-17861.

(74) Ma, H.; Liu, B.; Li, B.; Zhang, L.; Li, Y.-G.; Tan, H.-Q.; Zang, H.-Y.; Zhu, G. Cationic Covalent Organic Frameworks: A Simple Platform of Anionic Exchange for Porosity Tuning and Proton Conduction. J. Am. Chem. Soc. 2016, 138, 5897-5903.

(75) Beaudoin, D.; Maris, T.; Wuest, J. D. Constructing Monocrystalline Covalent Organic Networks by Polymerization. Nat. Chem. 2013, 5, 830-834.

(76) Dureckova, H.; Krykunov, M.; Aghaji, M. Z.; Woo, T. K. Robust Machine Learning Models for Predicting High $\mathrm{CO}_{2}$ Working Capacity and $\mathrm{CO}_{2} / \mathrm{H}_{2}$ Selectivity of Gas Adsorption in Metal Organic Frameworks for Precombustion Carbon Capture. J. Phys. Chem. C 2019, 123, 4133-4139.

(77) Krishna, R.; van Baten, J. M. In Silico Screening of MetalOrganic Frameworks in Separation Applications. Phys. Chem. Chem. Phys. 2011, 13, 10593-10616.

(78) Uribe-Romo, F. J.; Doonan, C. J.; Furukawa, H.; Oisaki, K.; Yaghi, O. M. Crystalline Covalent Organic Frameworks with Hydrazone Linkages. J. Am. Chem. Soc. 2011, 133, 11478-11481.
(79) Thompson, C. M.; Occhialini, G.; McCandless, G. T.; Alahakoon, S. B.; Cameron, V.; Nielsen, S. O.; Smaldone, R. A. Computational and Experimental Studies on the Effects of Monomer Planarity on Covalent Organic Framework Formation. J. Am. Chem. Soc. 2017, 139, 10506-10513.

(80) Li, Z.; Zhang, Y.; Xia, H.; Mu, Y.; Liu, X. A Robust and Luminescent Covalent Organic Framework as a Highly Sensitive and Selective Sensor for the Detection of $\mathrm{Cu}^{2+}$ Ions. Chem. Commun. 2016, 52, 6613-6616.

(81) Segura, J. L.; Royuela, S.; Mar Ramos, M. Post-Synthetic Modification of Covalent Organic Frameworks. Chem. Soc. Rev. 2019, 48, 3903-3945.

(82) Lu, Q.; Ma, Y.; Li, H.; Guan, X.; Yusran, Y.; Xue, M.; Fang, Q.; Yan, Y.; Qiu, S.; Valtchev, V. Postsynthetic Functionalization of Three-Dimensional Covalent Organic Frameworks for Selective Extraction of Lanthanide Ions. Angew. Chem., Int. Ed. 2018, 130, 6150-6156.

(83) Zhao, S.; Dong, B.; Ge, R.; Wang, C.; Song, X.; Ma, W.; Wang, Y.; Hao, C.; Guo, X.; Gao, Y. Channel-Wall Functionalization in Covalent Organic Frameworks for the Enhancement of $\mathrm{CO}_{2}$ Uptake and $\mathrm{CO}_{2} / \mathrm{N}_{2}$ Selectivity. RSC Adv. 2016, 6, 38774-38781.

(84) Huang, N.; Wang, P.; Addicoat, M. A.; Heine, T.; Jiang, D. Ionic Covalent Organic Frameworks: Design of a Charged Interface Aligned on 1D Channel Walls and Its Unusual Electrostatic Functions. Angew. Chem., Int. Ed. 2017, 56, 4982-4986.

(85) He, S.; Rong, Q.; Niu, H.; Cai, Y. Construction of a Superior Visible-Light-Driven Photocatalyst Based on a $\mathrm{C}_{3} \mathrm{~N}_{4}$ Active CentrePhotoelectron Shift Platform-Electron Withdrawing Unit Triadic Structure Covalent Organic Framework. Chem. Commun. 2017, 53, 9636-9639.

(86) Zhang, C.; Zhang, S.; Yan, Y.; Xia, F.; Huang, A.; Xian, Y. Highly Fluorescent Polyimide Covalent Organic Nanosheets as Sensing Probes for the Detection of 2,4,6-trinitrophenol. ACS Appl. Mater. Interfaces 2017, 9, 13415-13421.

(87) Nath, B.; Li, W.-H.; Huang, J.-H.; Wang, G.-E.; Fu, Z.-h.; Yao, M.-S.; Xu, G. A New Azodioxy-Linked Porphyrin-Based Semiconductive Covalent Organic Framework with $\mathrm{I}_{2}$ Doping-Enhanced Photoconductivity. CrystEngComm 2016, 18, 4259-4263.

(88) Neti, V. S. P. K.; Wu, X.; Deng, S.; Echegoyen, L. Synthesis of a Phthalocyanine and Porphyrin 2D Covalent Organic Framework. CrystEngComm 2013, 15, 6892-6895.

(89) Dokur, D.; Keskin, S. Effects of Force Field Selection on the Computational Ranking of MOFs for $\mathrm{CO}_{2}$ Separations. Ind. Eng. Chem. Res. 2018, 57, 2298-2309.

(90) Krishna, R. Screening Metal-Organic Frameworks for Mixture Separations in Fixed-Bed Adsorbers Using a Combined Selectivity/ Capacity Metric. RSC Adv. 2017, 7, 35724-35737.

(91) Park, J.; Rubiera Landa, H. O.; Kawajiri, Y.; Realff, M. J.; Lively, R. P.; Sholl, D. S. How Well Do Approximate Models of AdsorptionBased $\mathrm{CO}_{2}$ Capture Processes Predict Results of Detailed Process Models? Ind. Eng. Chem. Res. 2019, 59, 7097-7108.

(92) Daglar, H.; Keskin, S. Recent Advances, Opportunities, and Challenges in High-Throughput Computational Screening of MOFs for Gas Separations. Coord. Chem. Rev. 2020, 422, 213470.

(93) Altintas, C.; Keskin, S. Role of Partial Charge Assignment Methods in High-throughput Screening of MOF Adsorbents and Membranes for $\mathrm{CO}_{2} / \mathrm{CH}_{4}$ Separation. Mol. Syst. Des. Eng. 2020, 5, $532-543$

(94) Baker, R. W. Membrane Technology and Applications; John Wiley \& Sons: California, 2012.

(95) Wang, X.; Han, X.; Zhang, J.; Wu, X.; Liu, Y.; Cui, Y. Homochiral 2D Porous Covalent Organic Frameworks for Heterogeneous Asymmetric Catalysis. J. Am. Chem. Soc. 2016, 138, 1233212335 .

(96) Ding, S.-Y.; Dong, M.; Wang, Y.-W.; Chen, Y.-T.; Wang, H.-Z.; Su, C.-Y.; Wang, W. Thioether-Based Fluorescent Covalent Organic Framework for Selective Detection and Facile Removal of Mercury(II). J. Am. Chem. Soc. 2016, 138, 3031-3037. 
(97) Yang, Z.; Peng, X.; Cao, D. Carbon Dioxide Capture by PAFs and an Efficient Strategy to Fast Screen Porous Materials for Gas Separation. J. Phys. Chem. C 2013, 117, 8353-8364.

(98) Frost, H.; Snurr, R. Q. Design Requirements for Metal-organic Frameworks as Hydrogen Storage Materials. J. Phys. Chem. C 2007, 111, 18794-18803.

(99) Zhang, W.; Jiang, P.; Wang, Y.; Zhang, J.; Zhang, P. Bottom-Up Approach to Engineer Two Covalent Porphyrinic Frameworks as Effective Catalysts for Selective Oxidation. Catal. Sci. Technol. 2015, 5, 101-104.

(100) Kumar, S.; Wani, M. Y.; Arranja, C. T.; e Silva, J. d. A.; Avula, B.; Sobral, A. J. F. N. Porphyrins as Nanoreactors in the Carbon Dioxide Capture and Conversion: A Review. J. Mater. Chem. A 2015, 3, 19615-19637.

(101) Huang, N.; Krishna, R.; Jiang, D. Tailor-Made Pore Surface Engineering in Covalent Organic Frameworks: Systematic Functionalization for Performance Screening. J. Am. Chem. Soc. 2015, 137, 7079-7082.

(102) Yang, H.; Zhang, S.; Han, L.; Zhang, Z.; Xue, Z.; Gao, J.; Li, Y.; Huang, C.; Yi, Y.; Liu, H.; Li, Y. High Conductive TwoDimensional Covalent Organic Framework for Lithium Storage with Large Capacity. ACS Appl. Mater. Interfaces 2016, 8, 5366-5375.

(103) Zhao, R.; Zhao, L.; Deng, S.; Song, C.; He, J.; Shao, Y.; Li, S. A Comparative Study on $\mathrm{CO}_{2}$ Capture Performance of VacuumPressure Swing Adsorption and Pressure-Temperature Swing Adsorption Based on Carbon Pump Cycle. Energy 2017, 137, 495509.

(104) Su, F.; Lu, C. $\mathrm{CO}_{2}$ Capture from Gas Stream by Zeolite 13X Using a Dual-Column Temperature/Vacuum Swing Adsorption. Energy Environ. Sci. 2012, 5, 9021-9027.

(105) Su, F.; Lu, C.; Chung, A.-J.; Liao, C.-H. $\mathrm{CO}_{2}$ Capture with Amine-Loaded Carbon Nanotubes via a Dual-Column Temperature/ Vacuum Swing Adsorption. Appl. Energy 2014, 113, 706-712. 